\title{
Das vermeintliche Vorkommen von Elephas planifrons Falc. in Niederösterreich
}

\author{
(Eine kurze Anleitung zur Artbestimmung von Elephantenmolaren) \\ Von W. Soergel
}

In zwei Arbeiten ${ }^{1}$ ) und zwei kürzeren Mitteilungen ${ }^{2}$ ) hat neuerdings Günther Schlesinger versucht, das Vorkommen des bisher nur aus Indien bekannten Elephas planifrons für Niederösterreich zu beweisen. In der ersten Arbeit, die 1912 ungefähr gleichzeitig mit meiner Arbeit über diluviale Elephanten ${ }^{3}$ ) erschien, hat er, anschließend an die Bearbeitung zweier dem El. planifrons zugeschriebener Zahnfragmente, die gesamte Phylogenie der Proboszidier einer „kritischen" Prüfung unterzogen, die leider fast ausschließlich auf Literaturstudien beruhte und die Mängel dieser Arbeitsmethode besonders in den Kapiteln über die Stammesgeschichte der Elephanten deutlich zur Schau trägt. Die ältere Literatur über Elephanten ist ja für denjenigen, der zu seiner Arbeit nicht eigene Werte und Maße nitbringt, die er aus reichem Material, aus umfangreichen eigenen Untersuchungen geschöpft hat, ein Irrgarten gefährlichster Art.

1) Studien über die Stammesgeschichte der Proboszidier. Jahrb. d. K. K. Geolog. Reichsanstalt 1912, Bd. 62, Heft 1. Ein neuerlicher Fund von Elephas planifrons in Niederösterreich. Jahrb. d. K. K. Geol. Reichsanstalt 1913, Bd. 63, Heft 4.

${ }^{2}$ ) Über den Fund einer pliozänen Elephantenstammform (Elephas cf. planifrons Falc.) in Niederösterreich. Monatsblatt d. Ver. f. Landeskunde v. Niederösterreich. Jahrg. 1911, Nr. 16. E. planifrons vom Laaerberg und die Stratigraphie dar alten Flußterrassen von Wien. Verh. d. K. K. geolog. Reichsanstalt 1913, Nr. 15.

3) El. trogontherii Pohl. und El. antiquus Falc., ihre Stammesgeschichte und ihre Bedeutung für die Gliederung des deutschen Diluviums. Palaeontographica. Bd. LX. 
Es kann nicht wunder nehmen, daß ich in meiner, auf eigenen Untersuchungen an einem sehr umfangreichen Material aufgebauten Arbeit $\mathrm{zu}$ wesentlich anderen phylogenetischen Resultaten gelangte als G. Schlesinger. Der Briefwechsel zwischen Schlesinger und mir, der dem Erscheinen beider Arbeiten von 1912 folgte, galt zunächst fast ausschließlich der Bestimmung der beiden, besonders des von Dobermannsdorf stammenden Zahnfragments, dessen Bestimmung als El. planifrons mir schon auf Grund der 1. vorläufigen Mitteilung Schlesingers äußerst zweifelhaft erschien. Dieses Bedenken, dem ich vor Erscheinen der Schlesingerschen Hauptarbeit in meiner eben zitierten Arbeit unzweideutigen Ausdruck gab, wurde durch die Lektüre der Sch lesingerschen Abhandlung keineswegs behoben. Es zeigte sich, und der Briefwechsel bestätigte diese Beobachtung, daß Schlesinger nicht über die zu einer Bestimmung derartiger Zahnfragmente nötigen anatomischen Kenntnisse vom Bau des Elephantenzahnes, nicht über die nötige Erfahrung in der Wertung der einzeInen Bestimmungsmomente verfügte. Nachdem Schlesinger meinen Versuch, ihn über seine irrtümliche Ansicht von der Wurzel des Elephantenzahnes aufzuklären, auf eine in wissenschaftlichen Diskussionen immerhin ungewöhnliche Weise beantwortet hatte, brach ich den Briefwechsel aus leicht begreiflichen Gründen ab. Da die Arbeit schließlich überall Widerspruch hervorrief, so hielt ich eine Entgegnung vorläufig für überflüssig, begann aber, um ähnliche Fehlbestimnungen in Zukunft möglichst zu unterbinden, das Material für eine „Anleitung zur Bestimmung von Elephantenmolaren" zusammenzustellen. Andere Arbeiten haben mich leider bis heute an der Fertigstellung dieser Abhandlung gehindert.

Inzwischen ist neuerdings eine 2. Arbeit mit voraufgegangener kurzer Mitteilung von G. Schlesinger erschienen, die einen weiteren Fund von „El. planifrons" in Niederösterreich behandelt und in einem Anhang, der einer „Kritik der neuesten phylogenetischen Betrachtungen über Proboszidier" gewidmet ist, die phylogenetischen Resultate meiner Untersuchungen angreift: "Soergels Feststellungen sind lediglich auf eine Verkennung der Tatsachen zurückzuführen."

Da die oben in Aussicht gestellte "Anleitung" noch nicht abgeschlossen ist, und ihr Erscheinen sich noch einige Zeit hinausschieben dürfte, so sehe ich mich hier zu einer kurzen Klarstellung der durch Schlesingers Arbeiten verwirrten Verhältnisse veranlaßt. Ich tue das nicht aus Sorge, daß mein Schweigen falsch gedentet werden könnte ich kann der weiteren Entwickelung von unseren Kenntnissen über die Elephanten ruhigen Mutes entgegensehen und habe von Studien, wie 
sie Schlesinger veröffentlichte, für die Beweiskraft meiner Schlußfolgerungen nichts zu fürchten - sondern ich tue es aus dem Wunsche heraus, durch mein Schweigen nicht zu weiteren derartig oberflächlichen Arbeiten zu ermutigen, welche die eben erst auf eine sichere Basis gestellte Methode in der Bestimmung von Elephantenzähnen zu gunsten einer unexakten, auf unzureichenden Kenntnissen und mangelhaften Erfahrungen fundierten "Willkür" in den Hintergrund drängen. Wer die Literatur über fossile Elephanten einigermaßen kennt, der weiß, welche verhänguisvolle Rolle diese "Willkür" in der Entwickelung unserer Kenntnisse gerade hier gespielt hat.

Aus praktischen Gründen beschränke ich mich in den folgenden Ausführungen auf eine Diskussion über die von Schlesinger zu El. planifrons gestellten Zahnfragmente und die Argumente Schlesingers für seine Bestimmung. Eine kritische Besprechung der ganzen Arbeit oder auch nur aller von Elephas handelnden Teile würde einen unverhältnismäßig großen Raum beanspruchen.

Es ließ sich nicht umgehen, zur Klarlegung der wahren Verhältnisse bei Diskussion der einzelnen Bestimmungsmerkmale etwas weiter auszuholen, und ich habe es in Anbetracht dieser Notwendigkeit für das beste gehalten, jeweils in einem kurzen Abschnitt die allgemeine $\mathrm{Be}-$ deutung eines Merkmals an der Hand von Beispielen, wo es angeht, auch mit Zahlenmaterial zu erörtern und auf Grund der gewonnenen Basis dann die einzelnen in Rede stehenden Zahnfragmente zu begutachten, und die Schlesingersche Argumentation zu beleuchten.

Die allgemeinen Ausführungen über jedes Merkmal sind gewissermaßen als Ergänzungen aufzufassen zu meinen früheren Darlegungen über den Bau der Lamellen und den, der Molaren. Ich sah mich aber genötigt, hier vielfach sehr ins Einzelne zu gehen und Punkte zu erörtern, die bei aufmerksamem Studium auch beschränkten Materials jeder selbst finden kann, die Günther Schlesinger aber leider nicht fand.

Es ist mir im Rahmen dieser Mitteilung nicht möglich, das Gesagte überall durch Abbildungen zu unterstïtzen. Ich $m u ß$ in dieser Hinsicht auf die später erscheinende "Anleitung" und auf die entsprechenden Kapitel in Pohligs bekannter Monographie verweisen. Doch sind die erörterten anatomischen Verhältnisse und ihre Bedeutung für die Artbestimmung der Elephantenzähne im Einzelnen so einfach und klar, auch so leicht an einem relativ geringen Molarenmaterial, wie es jedes Institut besitzt, zu erkennen, daß der Mangel eines entsprechenden Darstellungsmaterials auch von Nichtspezialisten nicht sonderlich störend empfunden werden dürfte. 
W. Soergel,

Für die Beurteilung der Zahnfragmente ist das Alter der Fundschichten natürlich nicht ohne Bedeutung. Den palaeontologischen Erörterungen werde ich deshalb eine kurze Besprechung der geologischen Altersstellung der Schichten vorausschicken, soweit das allein nach den Ausführungen Schlesingers möglich ist. Wir besprechen also im folgenden:

1. Die Altersstellung der Terrassen von Dobermannsdorf und Laaerberg;

2. Die Artzugehörigkeit der Zahnfragmente von Dobermannsdorf und Laaerberg und ihre palaeontologischen Grundlagen.

\section{Die Altersstellung der Terrassen von Dobermannsdorf und Laaerberg}

Die Argumente, dic Schlesinger für ein höheres Alter beider Fundstellen als Oberpliozän anführt und besonders die Art, wie die einzelnen Momente zu Schlüssen herangezogen werden, können einer objektiven Kritik nicht genügen. Für die Beurteilung der Altersstellung der Dobermannsdorfer Schotter hat vor allen Dingen die Ansicht Schlesingers, daß die Fundstïcke sich dort auf sekundärer Lagerstätte befänden, daß sie in schon petrifiziertem Zustand in diese Schotter hineingeraten seien, völlig auszuscheiden. Die Momente der Erhaltung, die Schlesinger glaubt zu einer Begründung der sekundären Lagerstätte heranziehen zu können, beweisen in diesem Sinne absolut nichts und sind demjenigen, der mit großem Fossilmaterial vertraut ist, an vielen Knochen und Zähnen wohl bekannt, die nachweislich auf ihrer primären Lagerstätte gefunden wurden. Eine eingehendere Erörterung der diesbezüglichen Ausführungen Schlesingers auf S. 91 seiner Arbeit I eruibrigt sich.

Die weitere Beweisführung Schlesingers, die auf einer nicht weiter durch geologische Daten begründeten Parallelisierung der Dobermannsdorfer Schotter mit den Schottern von Mistelbach beruht, ist keineswegs überzengend. Denn an sich sagt die Tatsache, daß die Mistelbacher Schotter die Pikermi-Fauna führen, nichts aus über das Alter der Schotter von Dobermannsdorf. Hier hätte Schlesinger eine Brücke schlagen und den Beweis erbringen müssen, daß die Schotter von Dobermannsdorf denen von Mistelbach parallelisiert werden müssen. Gerade das wird nicht bewiesen, sondern unter dem Decknamen „Belvedereschotter" für beide Ablagerungen einfach behauptet. Aus der Tatsache, daß beide gleich rostrot oder okergelb gefärbt sind, geht eine Gleichaltrigkeit keineswegs hervor. Dieser Unsicherheit in der Argumentation 
entspricht auch die sehr vorsichtige Form, in der Schlesinger das Resultat seiner stratigraphischen Erwägungen zusammenfaßt:

„Mit Rücksicht auf die oben auseinander gesetzten Tatsachen ist es naheliegend, die gefundenen Skeletteile für Reste eines Tieres zu halten, welches spätestens im Mittelpliozän gelebt hat, da die Schotter von Dobermannsdorf in ihrem Gesamtcharakter mit den Mistelbacher Belvedereschottern, deren pontisches Alter feststeht, zwar völlig übereinstimmen, möglicherweise aber zufolge ihrer östlichen Lage etwas jünger sein können“. Füge ich hinzu, daß W. Freudenberg, der die Schotterablagerungen der Gegend aus Autopsie kennt, die Schotter von Dobermannsdorf für altquartär erklärt hat, so wird man zugeben, daß bei der Bestimmung des gefundenen Zahnrestes ein bestimmtes geologisches Alter zugunsten dieser oder jener Artbestimmung nicht in die Wagschale geworfen werden kann.

Das gleiche gilt für die Altersstellung der Fundschicht in der Laaerbergterrasse. Zur Altersbestimmung dieser Terrasse zieht Schlesinger einen Mastodonmolar heran, der ebenfalls der Laaerbergterrasse entstammt. Nach längerer Diskutierung resp. Vergleichung des Stückes, aus der für denjenigen, der mit der großen Unsicherheit vertraut ist, die Bestimmungen von Mastodonzähnen hänfig anhaftet, mindestens der beschränkte stratigraphische Wert des Objekts hervorgeht, kommt er zu dem Resultat, daß die Artzugehörigkeit des Stïckes am besten durch die Bezeichnung Tetrabelodon tapiroides Cuv. f. trans. ad. T. Borsoni Hays wiedergegeben werden könne und daß diese Form doch eher für ein mittel- als ein oberpliozänes Alter der Fundschicht beweisend wäre. Ich kann die stratigraphische Bedeutung zweier Mastodonzahnfragnente, die hinsichtlich ihrer Artbestimmung mehr oder weniger unsicher sind, nur sehr gering einschätzen und möchte bestimmte Schlüsse über das Alter der Terrasse aus ihnen nicht ableiten. Keinesfalls können sie als Beweis gelten für ein höheres Alter der Schotter als Oberpliozän.

Von besonderer Bedentung für die Altersstellung der Laaerbergterrasse ist die Tatsache, daß sie gegen die liegenden Kongeriensande mit einer deutlichen Diskordanz absetzt. Die Kongeriensande sind unterpliozänen Alters; von der Diskordanz wissen wir zwar nicht, welchem Zeitraum sie entspricht, doch beweist ihre weite Verbreitung, daß sie nicht nur von lokaler Bedeutung ist. Schlesingers Grund dafür, „daß die Diskordanz keinem besonders langen Zeitraum entsprach", besagt gar nichts. Aus diesem Tatsachenmaterial läßt sich meines Erachtens ungezwungen der Schlu $B$ ableiten, daß die Laaerbergterrasse mit dem Mastodon Borsoni sehr verwandten Proboszidier dem Oberpliozän zu- 
gehört, daß die Diskordanz gegen die Kongeriensande dem Mittelpliozän zeitlich entspricht.

Seine stratigraphischen Erörterungen resümierend sagt Schlesinger schließlich :

"Sicher ist, daß die Laaerbergterrasse nicht vor dem Mittelpliozän und nicht nach dem basalen Oberpliozän zur Ablagerung gelangte. Letzteres aus dem Grunde, weil der Horizont von E. planifrons jedenfalls älter sein muß als der seines Deszendenten E. meridionalis, einer oberpliozänen Art". Zur Altersbestimmung der Fundschicht wird also hier das zu bestimmende Fossil selbst mit herangezogen, die sonst vorhandenen géologischen und stratigraphischpalaeontologischen Daten genügen offensichtlich nicht, ein oberpliozänes Alter der Fundschicht auszuschließen.

Wie aber, wenn der dem El. planifrons zugesprochene Molar in Wirklichkeit dem El. meridionalis zugehörte? Dann stände einer Altersbestimmung der Laaerbergschotter resp. eines sehr erheblichen Teils dieser Schotter, als Oberpliozän nichts mehr im Wege.

Da Schlesinger den neuen Fund selbst zur Altersbestimmung der Fundschicht benutzt, so kann in diesem Falle das gewonnene Alter natürlich nicht als Argument für die Artbestimmung des Elephantenzahnes herangezogen werden. Lassen wir den Elephantenzahn vorläufig außerhalb unserer Diskussion, so erhellt aus Schlesingers Ausführungen nur, daß die Laaerbergschotter möglicherweise zum Teil dem oberen Mittelpliozän angehören könnten, mit viel größerer Wahrscheinlichkeit aber als eine Ablagerung des Oberpliozän zu deuten sind.

Aus unseren Erörterungen ergibt sich erstens, daß für keine von beiden Fundschichten ein höheres Alter als Oberpliozän erwiesen ist, zweitens, daß weder bei dem Zahnfragment von Dobermannsdorf noch dem vom Laaerberg zur Begründung der Artbestimmung geologische Momente resp. ein bestimmtes Alter der Fundschicht herangezogen werden können, daß die Bestimmung beider Zähne also lediglich auf Grund palaeontologischer Momente zu erfolgen hat.

\section{Die Artzugehörigkeit der Zahnfragmente von Dobermannsdorf und Laaerberg und ihre palaeontologischen Grundlagen}

Ia mir augenblicklich ein größeres Material von Zähnen des El. meridionalis zu speziellen Messungen nicht zur Verfügung steht, meine Notizen sowie entsprechende Literatur mir aber nicht zur Hand sind, 
so habe ich im folgenden meine allgemeinen Ausführungen über den Bau des Elephantenzahnes und die Bedeutung der einzelnen Merkmale vorwiegend mit Zahlen von den Zähnen des El. trogontherii von Süßenborn belegt. Bei dem prinzipiell gleichen Bau aller Elephantenzähne ist es ja, besonders in Hinblick auf die einfachen Verhältnisse, die wir zu erörtern haben, vollständig gleich, welche Art uns die Beweise liefert. Es kann sich in einzelnen Momenten nur um graduelle Unterschiede handeln, die im folgenden natürlich peinlichst berücksichtigt worden sind. Da die beiden strittigen Zahnfragmente von Dobermannsdorf und Laaerfeld letzten Unterkiefermolaren zugehören, so ist selbstverständlich gerade diese Zahnserie ausgiebig herangezogen worden. Aus didaktischen Gründen besprechen wir die verschiedenen zur Artbestimmung wichtigen Merkmale in folgender Reihenfolge:

1. Zahnhöhe.

2. Die Zahnwurzeln.

3. Die Form der Kaufläche.

4. Der Längen-Lamellen-Quotient.

5. Die Lamellenformel und ihre Ergänzung.

6. Der Verschmelzungstyp.

7. Schmelzstärke, Schmelzfältelung, mauerartiges Überragen der Schmelzfiguren über Zementintervalle.

8. Die Schmelzfigur.

9. Winkel zwischen Kaufläche und Kronenbasis.

Da manchem Interessenten die Schlesingerschen Arbeiten nicht ohne weiteres zur Hand sein dürften, habe ich es für zweckmäßig gehalten, den besten der besprochenen Zähne, den Zahn vom Laaerberg in den Textfiguren 6 und 7 nach Schlesingers Darstellung nochmals abzubilden, allerdings in einem kleineren Maßstahe.

\section{Zahnhöhe}

Die Höhe eines Elephantenzahnes wird gemessen von der Spitze der höchsten Lamelle bis zu deren Basis; die Zahnwurzel oder Teile der Wurzel bleiben unberücksichtigt, weil sie erstens im Laufe der Abkauung eines Zahnes sehr starken Veränderungen unterliegen, zweitens aber nur in sehr seltenen Fällen vollständig erhalten sind, und ihre Höhenangabe bei einzelnen besseren Zähnen daher nur sehr geringe Vergleichungs- und Auswertungsmöglichkeiten bietet. Die Lage der höchsten Lamelle im Verband eines vollständigen Zahnes ist bei den verschiedenen Zahnserien verschieden. Bei allen dem M III voraus- 
W. Soergel,

gehenden Zähnen außer dem vordersten Milchmolar liegt sie im Unterkiefer ungefähr zwischen der Mitte und dem vorderen Drittel eines Zahnes, im Oberkiefer mehr im vorderen Drittel. Die letzten Molaren sowohl des Unter- als des Oberkiefer's besitzen ihre größte Höhe stets am Ende des ersten Zahndrittels, Oberkieferzähne auch hier etwas weiter vorn als Unterkieferzähne. Nach hinten nehmen die Lamellen an Höhe allmählich $a b$, und zwar so stark, daß die letzte Lamelle - nicht etwa der Talon - in den meisten Fällen nur die halbe Höhe der höchsten Lamelle besitzt. Folgende Zahlen einiger letzter Unterkiefermolaren von Elephas trogontherii von Süßenborn mögen dies veranschaulichen.

Ein kaum angekauter M III mand. mit X 16 X zeigt folgende Höhen an den unangekauten Lamellen:

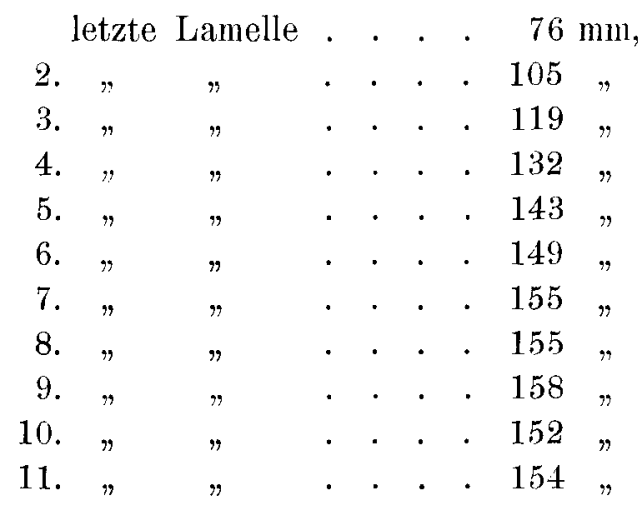

Die größte Höhe liegt an der 9. Lamelle von hinten, an der 7 . von vorn. Die letzte Lamelle ist weniger als halb so hoch als die höchste.

Mit zunehmender Abkauung resp. Erniedrigung der angekanten Lamellen rückt die größte jeweilige Zahnhöhe immer mehr nach hinten. Zumeist ist dann die letzte angekaute oder die erste unangekaute Lamelle die höchste. Ein M III mand. von El. trogontherii von Süßenborn mit X 19 X und 11 angekauten Lamellen zeigt folgende Höhenmaße der 12 letzten Lamellen:

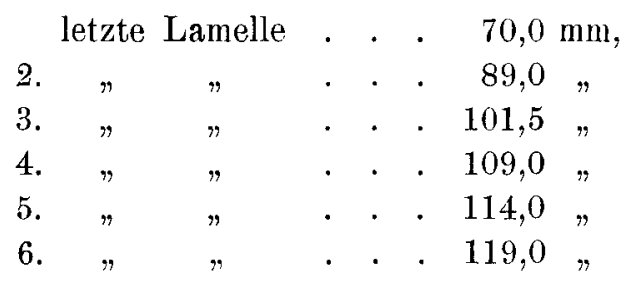




\begin{tabular}{|c|c|c|c|c|}
\hline 7. & letzte & Lamelle & . & 123,0 \\
\hline 8. & $"$ & $"$ & . & 128,0 \\
\hline 9 . & $n$ & $"$ & . & 131,0 \\
\hline 10. & $n$ & $"$ & . & 134,0 \\
\hline 11. & $n$ & $\%$ & . & 138,0 \\
\hline 12. & $n$ & , & . & 136,0 \\
\hline
\end{tabular}

Die größte Höhe ist also infolge Abkauung zurückgerückt auf die 9. Lamelle von vorn, auf die vorletzte angekante. Da dieser Lamelle durch Abkaunng, wie aus dem Verschmelzungsgrad der Schmelzfigur hervorgeht, sicherlich $20 \mathrm{~mm}$ fehlen, so hätte diese Lamelle unangekaut eine Höhe von $158 \mathrm{~mm}$ besessen, die beiden vorhergehenden Lamellen wahrscheinlich eine noch betrïchtlichere.

Ist es bei wenig angekauten Zühnen, an denen 6-8 Lamellen angekaut sind, noch möglich, die ursprïnglich größte Höhe des Zahnes in unangekautem Zustand zu erschließen, so wird das bei älteren Zähnen in dem Maße schwieriger als die Abkauung fortgeschritten ist. Die einzige Möglichkeit, hier zu einigermaßen-brauchbaren Resultaten zu gelangen, besteht darin, sich für die einzelnen Elephantenarten das Verhältnis zwischen den Höhen der höchsten und der letzten Lamelle auszurechnen. Mit Hilfe der erhaltenen Zahl wird man bei Zahnfragmenten aus der Höhe der unangekanten letzten Lamelle mit einer gewissen Sicherheit die ehemalige höchste Höhe des Zahnes erschließen können. Man wird zur Berechnung eines solchen Verhältnisses zweckmäßig die letzte, vor dem proximalen Talon stehende Lamelle heranziehen, da sie am längsten unangekaut, also in ihrer ganzen Höhe erhalten bleibt. Für die letzten Unterkiefermolaren des El. trogontherii fand ich auf Grund zahlreicher Messungen, daß die höchste Lamelle stets $1^{3 / 4}$ bis $2^{1 / 4}$ mal so hoch ist als die letzte Lamelle. Bei primitiveren Elephanten ist der Unterschied nicht so bedeutend, die Höhenabnahme von den vorderen nach den hinteren Lamellen allmählicher. Doch beträgt bei El. meridionalis (Val d'Arno) die Höhe der höchsten Lamellen noch immer das $1^{3 / 5}$ - bis 2 fache von der Höhe der letzten Lamelle. Bei El. planifrons dürfte dieses Verhältnis noch ein wenig zurückgehen, aber mindestens $1 \%$ bis $1^{3 / 5}$ betragen. Einen sicheren Aufschluß darüber kann das sehr spärliche und zum Teil sehr stark abgekaute Material an letzten Unterkiefermolaren dieser Art uns allerdings nicht verschaffen. Da die Art aber in allen Merkmalen der Dentition fortgeschrittener ist als selbst die höchststehenden Stegodonten, so wird man dies auch für die relativen Höhenverhältnisse annehmen müssen, nachdem es für die 
absoluten zutrifft. Ein letzter Oberkiefermolar - ein Unterkiefermolar steht mir augenblicklich nicht zur Verfügung, da es sich für uns hier aber ausschließlich um relative Verhältnisse handelt, so macht das kaum einen Unterschied - von Stegodon Airawana zeigt an den einzelnen unangekauten Jochen von vorn nach hinten folgende Höhenzahlen in $\mathrm{mm}$ :

$$
29,37,49,52,54,54,53,50,47,43,41,39,35 .
$$

Der höchste Punkt des Zahnes liegt also in Anfang des 2. Zahndrittels. Das höchste Joch hat eine Höhe ron $54 \mathrm{~mm}$. Das letzte niederste eine solche von $39 \mathrm{~mm}$. Das höchste Joch ist also das $1,38=1,4=1 \frac{2}{5}$ fache des letzten Joches. Diese relativen Höhenverhältnisse sind an letzten Ober- und Unterkieferzähnen ungefähr gleich, also ohne besondere Fehlermöglichkeit vergleichbar. Für den fortgeschritteneren El. planifrons werden wir nach dem Gesagten also annehmen dürfen, daß die Höhe der höchsten Lamelle mindestens das $1^{2 / 5}$ fache der letzten beträgt, sehr wahrscheinlich aber noch höhere Werte erreicht. $1^{2 / 5}$ bis $1^{3 / 5}$ sind also die mindesten Zahlen, die wir ohne Gefahr eines Irrtums bei Korrekturen oder Ergänzungen anwenden dürfen.

Die Höhe der Zähne einer Elephantenart von einem Fundort ist nicht unbeträchtlichen Schwankungen unterworfen; sie erreichen bei dem M III mand. des El. trogontherii von Süßenborn ein Ausmaß von $25 \mathrm{~mm}$. Die Höhe der letzten Lamelle dieser M III mand. schwankt zwischen 63 und $99 \mathrm{~mm}$, mit einem Durchschnitt von $79 \mathrm{~mm}$. Ist diese Fehlerquelle bei phylogenetisch älteren Elephanten wegen der allgemeinen geringen Zahnkronenhöhe absolut kleiner, so ist sie doch vorhanden und gestattet nicht, auf ganz geringe Höhenunterschiede großes Gewicht zu legen.

Bekanntlich gehört die Höhe der Elephantenmolaren unter diejenigen Merkmale, die eine von älteren nach jiingeren Formen gesetzmäßig sich steigernde Abänderung erfahren haben: je jünger die Art, desto höher die Molaren. Daraus erhellt ohne weiteres die Bedeutung der Zahnhöhe als Bestimmungsmoment von Molaren unsicherer Provenienz, unsicherer Altersstellung. Es ist selbstverständlich, und eigentlich nur gegenüber Arbeiten wie der Schlesingerschen zu betonen, daß die Benutzung dieses Merkmals mit einer gewissen Kritik zu geschehen hat.

Es dürfen zwei Zähne nur in der Höhe der ungefähr entsprechenden Lamellen verglichen werden, zwei Zähne der gleichen Art in der gleichen Lamelle. Zähne verschiedener Arten, deren Zähne verschiedene Lamellenzahlen besitzen, also El. planifrons und El. primigenius, sind nur in der Höhe gleicher Zahnteile zu vergleichen. Die Zahl der 
Lamellen sagt in einem solchen Falle natürlich nichts, da beispielsweise die 9. Lamelle von hinten bei El. planifrons im vordersten, bei El. primigenius im hinteren Zahnteile liegt. Diese 9. Lamelle bei El. planifrons würde ungefähr der 17.-23. Lamelle bei El. primigenius entsprechen. Ist der zu bestimmende Zahn völlig bis auf die letzte Lamelle abgekaut, so darf er nur mit entsprechend abgekauten Zähnen anderer Arten, nicht mit unangekauten Zähnen dieser Arten in der Höhe verglichen werden. Ebenso selbstverständlich dürfen nur Zühne gleicher Stellung im Gebiß in der Höhe miteinander verglichen werden, also M III mand. mit M III mand. usw., wenn aus diesen Vergleichen irgend welche Schlüsse zur Artbestimmung gezogen werden sollen. Jede Abweichung von dieser so einfachen Regel kann nur anf ungenügenden Kenntnissen vom Bau der Molaren und ihrer vom Grad der Abkauung abhängigen Höhenverhältnisse beruhen.

Gehen wir mit diesem Rüstzeug an die Bestimmung und Bewertung der Höhen der beiden ${ }^{1}$ ) vermeintlichen Planifronsmolaren.

An dem Zahnfragment von Dobermannsdorf ist das letzte Joch eben angekaut; es hat nach Schlesinger eine Höhe von $66 \mathrm{~mm}$, in ungekautem Zustand dürfte es sicher $70 \mathrm{~mm}$ hoch gewesen sein. Wie wir oben gesehen haben, ist das letzte Joch stets das niederste und beträgt bei El. meridionalis $1^{3 / 5}-2$, bei El. planifrons $1^{2 / 5}-1^{3 / 5}$ der größten, normalen Zahnhöhe. Zur Rekonstruktion der Normalhöhe unseres Zahnes können nur diese Werte in Betracht kommen. Wir wollen ein übriges tun und beide Werte zusammenziehen zu $1 \frac{2}{5}-2$. Daraus ergibt sich für unseren Zahn eine ehemalige Normalhöhe von 98-140 $\mathrm{mm}$, der Durchschnitt betrüge $119 \mathrm{~mm}$. Letzteres wäre die niederste Zahl, die mit Hilfe einer objektiven Rechnung zu gewinnen wäre, denn die später diskutierten Merkmale des Zahnfragmentes sprechen durchaus nicht gegen die Möglichkeit, die höheren Verhältniszahlen des El. trogontherii von $13 / 4-21 / 4$ auf unsern Zahn in Anwendung zu bringen, woraus eine ehemalige Normalhöhe von 125-157, also im Durchschnitt von 141 resultieren würde. Es ist in diesem Zusammenhange nicht unwichtig, daß die letzte Lamelle an M III mand. von El. trogontherii von Süßenborn häufig $70 \mathrm{mmm}$ und weniger beträgt, daßß unser Iobermannsdorfer Fragment in diesem Merkmal also sogar El. trogon-

1) Da für ein von Sehlesinger ebenfalls dem El. planifrons zugeschriebenes Zahnfragment von Krems a. d. Donau in jeder Beziehung das gleiche gilt wie für das Fragment von Dobermannsdorf, so habe ich auf eine besondere Diskutierung dieses Stückes hier wie in allen folgenden Abschnitten verzichtet. 
therii direkt entspricht. Schon bei El. meridionalis sind die letzten Lamellen der Unterkiefer M MI nur selten höher als $65 \mathrm{~mm}$ und dürften bei El. planifrons noch sebr erheblieh heruntergehen. Direkte Zahlenvergleiche sind aber nur nach vorangegangenen Messungen am indischen Originalmaterial möglich.

Vergleichen wir die erhaltene Normalhöhe von $119 \mathrm{~mm}$ mit den Höhen von M III mand. von El. meridionalis, so zeigt sich schönste Übereinstimmung. Nach Weithofer schwankt die Höhe bei 3 Zähnen zwischen 110 und $130 \mathrm{~mm}$. Wie die bei Weithofer in Klammern angegebenen Lamellen, an denen die Höhe gemessen wurde, beweisen, handelt es sich um durch Abkauung nur wenig erniedrigte Zähne. Bei dem Zahn mit $110 \mathrm{~mm}$ Höhe wurde die Höhe sogar am 10. letzten oder am 2.-4. Joch von vorn gemessen, also am normal höchsten Joch. Der Zahn von Dobermannsdorf stimmt also in den Höhenmaßen sehr gut mit El. meridionalis überein.

Wie verhält er sich nun El. planifrons gegenüber? Schlesinger gibt nach Falconer von 4 letzten Unterkiefermolaren dieser Art die Höhe an. Der 4. mit einer Höhe von $115 \mathrm{~mm}$ scheidet nach Schlesinger selbst aus, er gehört nicht El. planifrons an. Es bleiben 3 Zähne mit Höhen zwischen 64 und $97 \mathrm{~mm}$. Ein Zahn mit $89 \mathrm{~mm}$ Höhe am 9. Joch von hinten kann nur wenig angekaut resp. durch Ankaunng erniedrigt gewesen sein, ein anderer von $97 \mathrm{~mm}$ am 5 . letzten Joch dürfte bei geringer Abkauung etwas höher gewesen sein. An eine Höhe von $119 \mathrm{~mm}$ reicht jedenfalls kein Zahn heran.

Aus diesem Vergleich ergibt sich, daß der Zahn von Dobermannsdorf mit El. meridionalis in der Höhe weit besser übereinstimmt als mit El. planifrons. Die Zahnhöhe ist nicht für, sondern gegen die Zugehörigkeit dieses Zahnes zu El. planifrons beweisend.

Der besser erhaltene und weniger abgekaute Zahn von Laaerberg besitzt an der 2. letzten Lamelle eine Höhe von $98 \mathrm{~mm}$ außen, $102 \mathrm{~mm}$ innen, an der letzten Lamelle eine solche von $93 \mathrm{~mm}$. Vor der Ankauung muB die 2. letzte Lamelle, nach dem Verschmelzungsgrad der Schmelzfigur zu urteilen, mindestens $108 \mathrm{~mm}$ hoch gewesen sein. Berechnen wir auf Grund unserer Verhältniszahlen die mutmaßliche Höhe des unangekauten Zahnes, so erhalten wir eine Normalhöhe von 130 bis $186 \mathrm{~mm}$. Der letzte Wert erscheint in Anbetracht der übrigen Merkmale des Zahnes allerdings zu hoch, doch muß mit einer Höhe von 130-145 mm gerechnet werden. Das läßt sich auch aus der Kurve wahrscheinlich machen, die die Spitze der beiden letzten Lamellen verhindet. Der Anstieg von der letzten zur vorletzten Lamelle von 93 
auf 105 resp. 108 läßt mit großer Wahrscheinlichkeit eine Normalhöhe von ca. 140 am Ende des ersten Zahndrittels vermuten. Die Höhe der letzten Lamelle von $93 \mathrm{~mm}$ muß überhaupt als recht beträchtlich bezeichnet werden, da sie von El. meridionalis, ja selbst El. trogontherii an M III mand. nur sehr selten erreicht wird.

Mit dem errechneten Höhenwert fällt unser Zahn mit El. meridionalis zusammen und weit außerhalb der allerdings spärlich belegten Schwankungsbreite des El. planifrons.

Die Höhe des Zahns vom Laaerberg spricht also vollkommen gegen eine Bestimmung als El. planifrons.

Wie verfährt nun Schlesinger in der Auswertung der Zahnhöhe? Er behandelt die Frage besonders eingehend bei dem Dobermannsdorfer Zahnfragmente. Ich lasse ilın am besten selbst zu Worte kommen.

S. 95 :

„Die Schmelzbögen reichen nach unten bis zu einer ziemlich geradlinigen Grenze, welche durch die Höhenwerte der Joche (s. S. 94) bestimmt ist. Da nun infolge der ganz eigenartigen Zahnung der Elephanten die Molaren immer vorn mehr niedergekaut sind als hinten, ist die Kronenhöhe je nach dem Abkaungsstadium an den einzelnen Jochen verschieden. Die tatsächliche Höhe können wir nur in jenen Fällen ermitteln, wo wenigstens eine Lamelle noch unangekaut oder in einem geringen Abkauungsstadium erhalten ist; im letzteren Falle läßt sich die Höhe leicht finden, da die Joche bogenförmigen Scheiben entsprechen und aus der Neigung der beiden Bogenschenkel gegeneinander der Kulminationspunkt einfach rekonstruiert werden kann."

In Anmerkung 4 auf S. 107 heißt es:

"Die vorderen Joche sind ja zweifellos (mit Rücksicht auf die weiter vorgeschrittene Abrasion) bis auf etwa $80 \mathrm{~mm}$ zu ergänzen (4. 11. 5. Joch)."

Weiter S. 101:

"Die Kronenhöhe, welche infolge des Umstandes, daß das erste Joch (nach dem Talon) eben erst angekaut ist, jeden bei weitgehender Abkaung immer berechtigten Zweifel ausschließt, bleibt weit hinter den für $\mathrm{M} \% / 3$ von El. meritionalis angegebenen Maßen zurïck."

SchlieBlich S. 102 :

„Die aus den vorstehenden Zahlen (eine Tahelle der Höhenmaße von mandibularen und maxillaren M II und M III des El. meridionalis von Val d'Arno, Einfügung von Soergel) ersichtliche Tatsache, daß selbst bei den einen primitiven Charakter bewahrenden zweiten 
Molaren von El. meridionalis die Kronenhöhe in unangekautem Zustand nicht unter $100 \mathrm{~mm}$ herabsinkt, macht eine Vereinigung unseres Stückes mit dieser Spezies unmöglich."

Bei den Zahnfragmenten von Laaerberg diskutiert Schlesinger die Höhe des Zahnes als Bestimmungsmerkmal nicht ausführlicher und verweist auf die Ausführungen bei dem Zahn ron Dobermannsdorf. Die Merkmale des Laaerberger Zahmes - also auch seine Höhe - sind nach ihm aber „so unzweideutig, daß ein Zweifel (an seiner Bestimmung als El. planifrons, Soergel) völlig müßig ist". Schlesinger hält also die Höhe des letzten, vor dem proximalen Talon gelegenen Joches für die normale Kronenhöhe eines Elephantenmolaren und nimmt an, daß alle Joche eines Zahnes fast die gleiche Höhe besitzen. Er vergleicht seinen auf solch irrtümlicher Basis gewonnenen Höhenwert mit der richtig gemessenen Kronenhöhe von verschieden stark, durchgehends aber weniger und viel weniger abgekauten Ober- und Unterkiefer M III und M II, also zweier ganz verschieden zu wertenden Zahnserien, von El. meridionalis und kommt zu dem Schluß, daß eine Vereinigung des Zahnes von Dobermannsdorf (und für den Laaerberger soll das gleiche gelten) mit El. meridionalis wegen der Unterschiede in der Zahnhöhe nicht möglich sei.

Weitere Kommentare zu Schlesingers Ausführungen über die Zahnhöhe erscheinen überflüssig!

\section{Die Zahnwurzeln}

Zur Unterscheidung der einzelnen Elephantenarten sind die Zahnwurzeln fast vollkommen wertlos. Dieser Unstand sowie die starke Abänderung, die sie im Laufe der Abkaunng eines Zahnes erleiden, nicht zum geringsten schließlich die Tatsache, daß sie unter 100 Zähnen vielleicht bei fünf einmal leidlich erhalten sind, hat es bewirkt, daß der Wurzel der Elephantenzähne von den meisten Autoren geringe Beachtung geschenkt wurde. Ich faßte die Resultate meiner Untersuchungen über diesen Gegenstand in meiner oben zitierten Arbeit folgendermaßen zusammen.

„Die Zahnwurzeln geben mit einer Ausnahme - die M. M. III des jüngeren El. antiquus - keinen Anhaltspunkt für Speziesbestimmung, sie sind bei den vorliegenden 4 Arten (El. meridionalis, antiqus, trogontherii, primigenius) immer in der gleichen Weise ausgebildet. Bei allen Zähnen zerfällt die Wurzelpartie in einen vorderen kleineren und einen hinteren größseren Teil, der wenigstens bei den echten Molaren stets 
in zahlreiche, in zwei Reihen angeordnete kleine Wurzeläste aufgelöst ist (siehe Fig. 1 dieser Arbeit, Einf.). Der vordere Teil trägt an den Milchmolaren 1-2, an den echten Molaren 2-3, selten 4 Lamellen (das ist natürlich verschieden, je nach dem geologischen Alter der Art, primitive Arten tragen weniger, fortgeschrittene mehr Lamellen auf dem vorderen Wurzelteil, stets aber dem Verhältnis entsprechend, in dem ihre ganzen Lamellen-zahlen für jede Zahnserie zueinander stehen. Zusatz v. Verf.) er ist manchmal gespalten. Die zahlreichen Wurzeläste des hinteren Teils gehen sämtlich vom Zahne aus und lassen in der Mediane zumeist eine

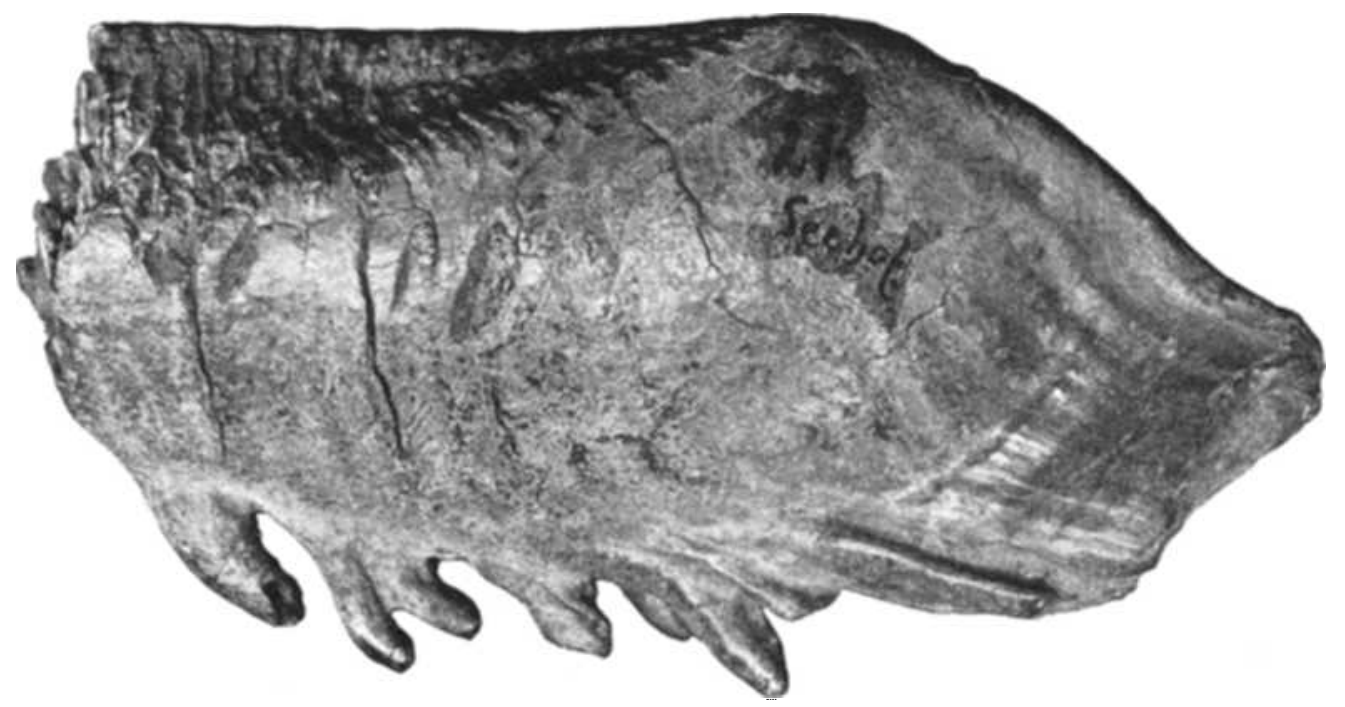

Fig. 1. Letzter Unterkiefermolar von Elephas primigenius Blumb. aus Niederterrassenschotter. Seehof bei Frankfurt a. Main. Original im Senckenberg-Museum, Frankfurt. Fast 1/2 natürl. Größe.

Fläche frei, die „Zahnkronenbasis", die sich im allgemeinen bei Mandibelund Maxillenmolaren nach hinten mehr oder weniger verbreitert. Bei Ober- und Unterkieferzähnen zeigt sich ein Unterschied im Verhalten der Wurzeläste. Bei Oberkiefermolaren sind die äußeren meist schon bald zu einem wandartigen Gebilde verschmolzen, während die inneren länger frei herausragen. Bei Unterkiefermolaren sind die inneren eher verbunden, während die äußeren frei bleiben.

Eine bestimmte, alle Verhältnisse umgreifende Gesetzmäßigkeit ließ sich allerdings nicht beobachten. In dem Maße, wie der Zahn abgekaut wird, verschmelzen die einzelnen Wurzelreste und bilden schließlich an stark abgekauten letzten Molaren eine oft sehr hohe Dentinwand." 
Diese Ausführungen haben selbstverständlich für alle Elephanten, also auch El. hysudricus, namadicus, africanus, indicus und planifrons Gültigkeit.

Da ungefähr $75 \%$ aller gefundenen Elephantenzähne letzte Molaren sind und unter diesen wiederum stärker abgekaute eine große Häufigkeit besitzen, so beansprucht die Wurzelbildung gerade der letzten Molaren ein gewisses praktisches Interesse. Da ferner die beiden strittigen Zähne aus Niederösterreich eben dieser Zahnserie angehören, so müssen wir

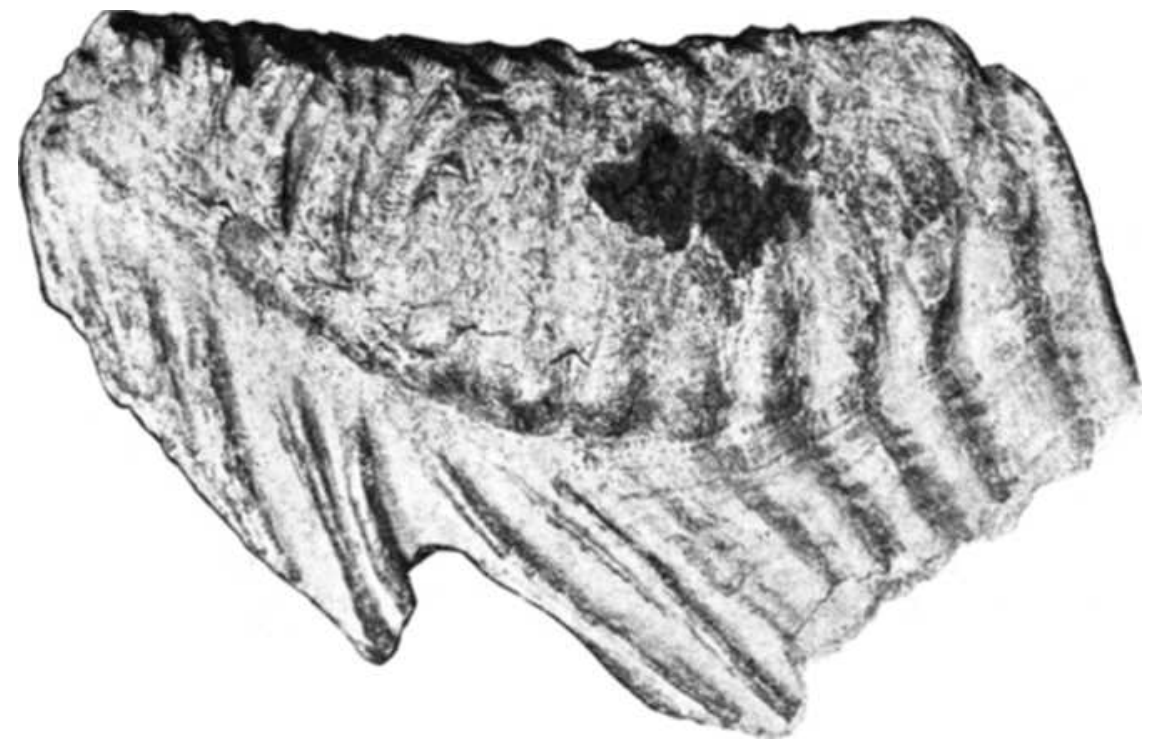

Fig. 2. Letzter Unterkiefermolar von Elephas primigenius Blumb. aus Niederterrassenschotter. Seehof bei Frankfurt a. Main. Original im Senckenberg-Museum, Frankfurt. ca. $1 / 2$ natürl. Größe.

uns im folgenden etwas eingehender mit den Abänderungen der Zahnwurzel beim M III und der Bildung der „Dentinwand“ beschäftigen.

Wie oben schon gesagt, beginnen bei letzten Molaren mit fortschreitender Abkauung die einzelnen Wurzeläste, die infolge der Vorwärtsbewegung des Zahnes sich immer stärker nach hinten biegen und dem Zahn anschmiegen, zu einem wandartigen Gebilde zu verschmelzen. Im ersten Stadium - bei Mammutzähnen nach Abkauung von 4--6 Lamellen - bildet sich auf beiden Seiten an der Zahnunterseite eine relativ dünne Wand, die in der Mitte die "Zahnkronenbasis" einschließt, im hintersten Zahnteil aber häufig schon zu einer kompakteren Masse 
verwachsen ist. Ein solches Stadium zeigt uns Fig. 1, im vorderen Zahnteil die noch frei herausragenden Wurzeläste, hinten die Dentinwand. Die Höhe einer solchen Dentinwand entspricht in dem ersten Stadium ungefähr derjenigen der Wurzeläste. Bei fortschreitender Abkauung wird der Wurzelpartie mehr und mehr Dentin zugeführt, die einzelnen

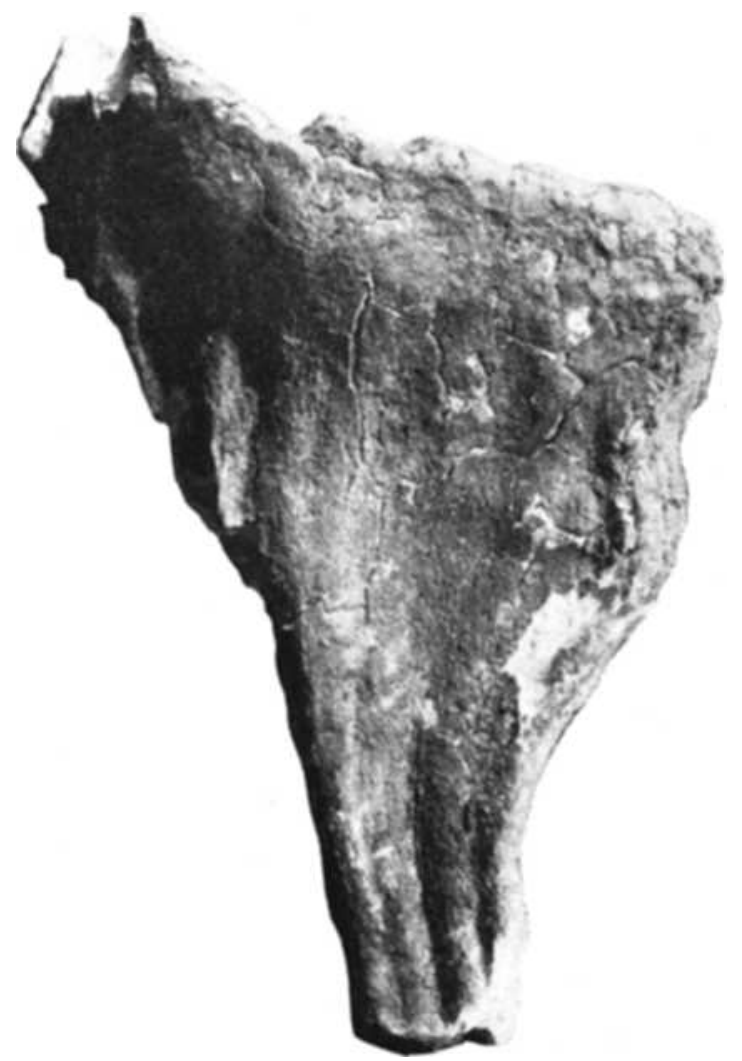

Fig. 3. Letzter Unterkiefermolar eines sehr alten Individuums von Elephas primigenius Blumb. aus jüngerem Löb. Emmendingen in Baden. Original im Großh. Naturalienkabinet zu Karlsruhe. ca, $1 / 2$ natürl. Größe.

(Nach Soergel, Aussterben und Jagd, G. Fischer, Jena, 1912.)

Wurzeläste treten allmählich als Komponenten der Dentinwand zurück siehe Fig. 2 - und letztere wächst bei fortdauernder Dentinzufuhr zu sehr beträchtlichen Höhen, bis $20 \mathrm{~cm}$ an, wie es z. B. Fig. 3 zeigt. Indem an der Zahnkronenbasis sowohl als an der Dentinwand innen fortwährend Dentin abgesetzt wird, rückt die Zahnkronenbasis einmal immer tiefer hinunter und wird andererseits sehr stark eingeengt. Sie bildet 
schließlich nur noch eine sehr schmale Fläche, die häufig allseitig von Dentin eingeschlossen ist. Da im Normalzustand resp. an wenig angekauten Zähnen die Zahnkronenbasis mit den auf- und absteigenden unteren Endigungen der Lamellen eine wellig gekrümmte Fläche bildet, so zeigt sie auch nach ihrer durch Dentinauflagerung erfolgten Reduktion noch dieses auf und ab in kleinen Buckeln und Mulden, die eben den ehemaligen Tälern zwischen zwei Lamellen und den Lamellen selbst entsprechen. Meist zeigt die Dentinwand, wie z. B. Fig. 2, in der Vertikalen eine Gliederung in regelmäßigen Furchen und Erhebungen, die wie eine Verlängerung der Lamellen und Zementintervalle nach unten aussehen. Diese Oberflächenskulptur der Dentinwand erklärt sich folgendermaßen :

Man beobachtet häufig, daß im Elephantenunterkiefer die Innenwand der Alveole, in der der letzte Molar gesessen hat, wie ein Wellblech in vertikale Furchen und zwischen den Furchen verlanfende Grate gegliedert ist.

Passen wir den Zahn in die Alveole, so sehen wir, daß die Furchen den Lamellen, die Grate den Zementintervallen entsprechen. Diese Bildungen an der Alveolenwand sind natürlich im allgemeinen durchaus vergänglicher Art, da ja der Zahn neben seiner Aufwärtsbewegung vor allem eine horizontale Bewegung ausführt, die diese Innenskulptur der Alveole immer wieder verwischen und umgestalten muß. Wir wissen aber, daß letzte Molaren, wenn sie bis zu einem gewissen Grad abgekaut und vorwärts geschohen sind, sich nicht mehr vorwärts, sondern nur noch aufwärts bewegen. Von diesem Moment an wächst die Alveole in dem Maße zu, als der Zahn abgekaut resp. verbraucht und verkleinert wird. Hat der Zahn aber seine Vorwärtsbewegung eingestellt, so ist kein Grund für eine schnelle Verwischung der Lamellenabdrücke in der Alveolenwand vorhanden, da der Zahn sich auf dieser, sagen wir Hohlschiene, nur hoch schiebt. In gleichen Tempo wird aber unten Dentin abgesetzt, das natürlich an seiner Oberfläche die Skulptur der Alveolenwand annehmen muß.

Ganz alte Individnen kauen schließlich, nachdem auch der Schmelz der letzten Lamelle verbraucht ist, nur noch auf dieser Dentinwand, die eine sehr stattliche Höhe - bis $20 \mathrm{~cm}$ - erreichen kann. Der in der Fig. 3 wiedergegebene Zahn besitzt eine solche Kaufläche ohne jede Spur von Schmelz. Es ist schließlich selbstverständlich, daß diese Dentinwand als Neu- oder Kompensationsbildung mit der Zahnwurzel als solcher gar nichts mehr zu tun hat. Sie ist ein "Zahnersatz", gewissermaßen ein sekundärer, eigenartiger Zahn. 
Wenn die Zahnwurzeln resp. die Dentinwand des MIII auch für Artbestimmungen keine Anhaltspunkte bieten, so geben sie uns doch wertvolle Aufschlüsse über das spezielle und individuelle Alter eines Zahnes und sind in vielen Fällen, zum Beispiel bei schätzungsweisen Ergänzungen der Lamellenzahl außerordentlich wichtig, ja die einzigen, ausschlaggebenden Kriterien.

An unseren beiden niederösterreichischen Molaren sieht man an der Gestaltung des unterhalb der Zahnkrone liegenden Zahnteils sofort, daß es sich um Reste individuell sehr alter Zähne handelt.

Der Zahn von Dobermannsdorf zeigt eine regelrechte Dentinwand. Sie ist unten abgebrochen und läBt auf ihrer Unterseite die auf eine schmale bandförmige Fläche reduzierte Zahnkronenbasis mit schwachen Mulden und Buckeln erkennen. Gut $1 / 3$ der Dentinwand sind durch Bruch verloren gegangen.

Der Laaerberger Zahn gehörte einem etwas jüngeren Tier an. Die Bildung einer Dentinwand hat allerdings auch hier, soweit die Figur ein sicheres Abschätzen gestattet, in nicht unbeträchtlichem Maße eingesetzt, aber im vorderen Zahnteil können wir noch deutlich mehr oder weniger isolierte, noch nicht in die Dentinwand fest eingeschmolzene Wurzelteile erkennen, die allerdings infolge Abbruchs nur unvollständig erhalten sind. Am hinteren 'Teile ist von der Dentinwand sehr viel verloren gegangen, die unter der 2. letzten Lamelle eine Höhe von $90-100 \mathrm{~mm}$ besessen haben $\mathrm{mu}$.

$\mathrm{Zu}$ weiteren direkten Feststellungen ist die "Wurzelpartie" der beiden Zähne nicht geeignet. Es lassen sich lediglich später eingehender zu erörternde Schlüsse auf die Anzahl der möglicherweise fehlenden Lamellen ziehen.

Die eben beschriebenen Verhältnisse der Zahnwurzel, die allerdings nicht aus der Literatur, sondern lediglich auf Grund ron Studien am fossilen Material und in Anbetracht der sehr selten genügenden Erhaltung der Wurzelteile, an einem sehr umfangreichen fossilen Material erschlossen werden können, hat Schlesinger in bedauerlicher Weise völlig verkannt. Die stark verletzte Dentinwand des Dobermannsdorfer Molaren hat er für die intakte Zahnwurzel angesprochen und weitgehende Schlüsse auf die Höhe dieser "Wurzel" begründet. In gleichem Sinne hat er die Dentinwand des Laaerberger Molaren bewertet. Bei dieser Gelegenheit glaubt er eine sehr bedeutungsvolle Entdeckung gemacht zu haben; er konstruiert ein Verhältnis zwischen Zahnkronenhöhe und Wurzelhöhe:

„Der Wert und die Wichtigkeit dieses Verhältnisses von Kronen und Wurzelhöhe für die Bestimmung der Elephanten- 
molaren und insbesondere für die phylogenetische Betrachtung dieser Tiergruppe wurde von sämtlichen Autoren bisher übersehen.

Es ist das um so erstaunlicher, als H. Falconer in seiner Fauna antiqua Sivalensis eine Zahl von Schnitten verschiedener Zähne von Mastodon, Stegodon und Elephas abbildet und auf die Zunahme der Kronenhöhe im Verlauf der Entwickelung des Elephantenstammes durch Wort und Bild hinweist, ferner H. Pohlig von tapinodisken und hypselodisken Molaren spricht. Nie wurde die Wurzel mit in Rücksicht gezogen und gerade auf sie kommt es an."

Ich glaube, daß „sämtliche Autoren“ Schlesingers pathetisch vorgetragenen Vorwurf leichten Herzens werden ertragen können, daß sie in der Stammreihe der Elephanten mit vollstem Recht der wachsenden Kronenhöhe die größte Beachtung schenkten, der sich sehr langsam reduzierenden Wurzel geringeren Wert beimaßen. Ändert sich das Verhältnis zwischen 2 Größen, so wird man die Größe als urhebend für die Veränderung und als besonders wichtig erkennen, die sich am weitesten von ihrem alten Wert entfernte und eben dadurch die neue Situation schuf. Das ist in unserem Falle aber in überragendem Maße die Zahnkrone, die sich beispielsweise von El. planifrons bis zu El. primigenius mehr als verdoppelte, während die Verkürzung der wirklichen Wurzeln auf diesem Wege nur sehr geringe Fortschritte machte. Nennenswerte Unterschiede in der Länge der wirklichen Wurzeln, die bei Elephas im Laufe der Entwickelung ihre eigentliche Bedeutung als Befestigungsmittel fast völlig eingebüßt haben und zu einer Art Gleitschlitten für die Bewegung der Molaren geworden sind, sind eigentlich nur zwischen Elephas auf der einen. Stegodon und Mastodon auf der anderen Seite zu konstatieren. Innerhalb des Elephantenstammes selbst sind die absoluten Unterschiede recht unbedeutend und metrisch kaum festzulegen. Wie sollte man auch diese wirklichen Wurzeln messen. Welche Wurzeln, die des ersten Zahndrittels oder die des zweiten, soll man miteinander vergleichen? Was für Resultate schließlich sind zu erwarten von den wenigen Messungen, welche die äußerst selten intakte Erhaltung der wirklichen Wurzeln gestatten würde? Wie gesagt, man kann innerhalb des Elephantenstammes die geringen Veränderungen in der Wurzellänge, die vorhanden sein mögen, unbekümmert vernachlässigen und nach wie vor der gewaltigen Höhenzunahme der Zahnkrone die ausschlaggebende Bedeutung in phylogenetischen Wertungen zuerkennen.

Ich kann deshalb keineswegs der Schlesingerschen Ansicht zustimmen, daß es gerade auf die Wurzel ankäme, und befinde mich mit 
meiner Auffassung in der Gesellschaft von Forschern, die ausnahmslos mit dem Bau der Elephantenzähne viel besser vertraut waren als Günther Schlesinger.

Um mit diesem tief bedauerlichen Irrtum Schlesingers zum Schluß zu kommen:

Schlesinger berechnet aus der falschen Kronenhöhe (siehe Abschnitt 1) und aus der falschen "Wurzel"höhe, daß beide Teile, „Krone“ und "Wurzel", sich zu ungefähr gleichen Teilen am Aufbau des Zahnes beteiligen, und mißt diesem Resultat unter allen anderen Merkmalen für die Bestimmung des Zahnes als El. planifrons die größte Bedeutung bei. Ja, es ist für ihn letzten Endes, nachdem er das Resultat mit einigen weiteren falschen Messungen an Abbildungen der Literatur verglichen hat, beweisend für' die Artbestimmung, wie aus folgenden Sätzen hervorgeht:

"Was uns die Gesamtbetrachtung der Kaufläche (siehe Abschnitt 7 und 8 dieser Arbeit, Soergel) und in gleicher Weise die Rekonstruktion der Lamellenformel (siehe Abschnitt 5 dieser Arbeit, Soergel) wahrscheinlich macht, erhebt der Befund über das phyletisch so wichtige Verhältnis zwischen Krone und Wurzel zur vollen Gewißheit ${ }^{1}$ ), daß unser Zahn auch mit den ältesten Vertretern von El. meridionalis nichts zu tun hat, vielmehr einen weit primitiveren Typ repräsentiert."

Im gleichen unmöglichen Sinne wie beim Dobermannsdorfer Zahn hat Schlesinger die "Kronen-Wurzelhöhe" beim Laaerberger Zahn verwertet.

Das Hauptargument Schlesingers für die Bestimmung des Dobermannsdorfer und damit auch des Laaerberger Zahnes als El. planifrons Falc. hat sich also als eine starke Irrung erwiesen.

\section{Die Form der Kaufläche}

Ich habe früher a. a. O. darauf hingewiesen, daß der Umriß der Einzellamelle resp. die Stärke der Lateralpfeiler einen Einfluß auf die Form der Kaufläche besitzt. Heute möchte ich hinzufügen, daß die Kaufläche und ihr bei fortschreitender Abkaunng sich abändernder Umriß lediglich eine Funktion des Lamellenumrisses darstellt. Beschränken wir unsere Erörterungen auf die letzten Unterkiefermolaren.

Jede nicht angekaute Lamelle eines Elephantenzahnes nimmt von oben nach unten allmählich an Breite $\mathrm{zu}$, erreicht die größte Breite

1) Im Originaltext nicht gesperrt. 
zwischen $1 / 3-1 / 2$ Lamellenhöhe und verschmälert sich dann, wie nebenstehende Fig. 4 zeigt, mehr oder weniger nach der Zahnkronenbasis zu. Diese Grundform der Lamelle ist graduell natürlich sehr verschieden entwickelt, einmal bei verschiedenen Arten, dann aber auch bei verschiedenen Individuen der gleichen Art. Jede Kaufläche, mag der Zahı wenig oder sehr stark angekaut sein, schneidet nun die einzelnen an-

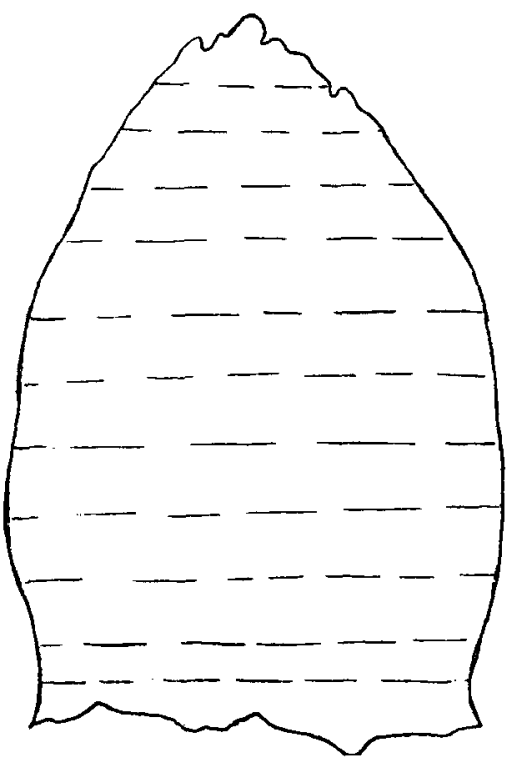

Fig. 4. Lamelle eines letzten Unterkiefermolaren von Elephas trogontherii Pohl.

Die horizontalen Linien markieren die verschiedenen Höhen, in welchen eine Kaufläche die aufeinander folgenden Lamellen schneidet: Die unterste Linie bezeichnet die Schnitthöhe bei der 1. Lamelle von vorn, die zweite Linie von unten die der zweiten von vorn u. s. f. gekauten Lamellen in verschiedener Höhe, die hintersten oben, wo sie noch schmal sind, die mittleren tiefer bis zu der Stelle, wo sje ihre größte Breite besitzen, die vordersten unter der Stelle ihrer größten Breite, bei zunehmender Verschmälerung. Die Linien $1-8$, die durch die in Fig. 4 dargestellte Lamelle gezogen sind, sollen andeuten, wo eine Kaufläche, die 1., 2., 3. und so fort Lamelle schneidet. Die Form der Kaufläche ist also im Prinzip die gleiche wie die der Lamellen, sie kann aber durch die Größe der Zementintervalle als eine Verkürzung oder eine Verlängerung dieses Grundtyps erscheinen, auf jeden Fall ist sie oval. Da diese Tatsache für jede Kaufläche zutrifft, mag sie nun im vorderen Zahnteil liegen oder im hinteren, mögen wenig Lamellen angekaut sein oder infolge Abkauung im vorderen Zahnteil schon eine Anzahl verschwunden, so müßte jede Kaufläche mehr oder weniger oval sein und sich nach vorn verschmälern - wenn alle Lamellen von der 1. bis zur letzten gleich breit wären. Da aber vom vorderen Drittel eines M III mand. die Lamellen nach hinten zu schmäler werden in dem Maße, als der Zahn sich verschmälert, so kompliziert sich die Gestaltung der Kaufläche resp. ihre Ableitung aus dem Lamellenumriß. Es werden nämlich die mittleren resp. hinteren Lamellen an ihrer breitesten Stelle nicht mehr breiter sein als die nächst vorhergehenden Lamellen unterhalb ihrer größten Breite. Das heißt, je 
tiefer die Kaufläche gelegt wird, je mehr sie sich in den mittleren und hinteren Zahnteil verlegt, desto weniger wird ein ovaler Kauflächenumriß hervortreten zugunsten einer mehr rechteckigen Kaufläche, die nur an den vordersten Lamellen eine kleine Verschmälerung zeigt. Einen solchen Umriß muß die Kaufläche jeden Zahnes dann erreichen, wenn sich die Lamellen des 2. und 3. Viertels in Funktion befinden. Bei zunehmender Abkauung wird auf der Kaufläche die allgemeine Verschmälerung des Zahnes nach hinten immer mehr hervortreten, so daß Kauflächen vollständig abradierter Zähne eine birnförmige Gestalt erhalten. Es zeigt also, je nach der Abkauung, die Kaufläche letzter Molaren folgende Gestalt: rund bis oval, wenn das 1. Zahnviertel in Funktion ist, oval, wenn das 1. und 2. Zahnviertel in Funktion sind, oval-rechteckig bis rechteckig, wenn das 2. und 3. Viertel in Funktion sind, rechteckig-birnförmig und oval-birnförmig, wenn das 3 . und 4. Viertel in Funktion sich befinden, birnförmig, wenn das 4. Viertel in Funktion ist.

Diese Unterschiede werden sich an wenigsten bei den Arten geltend machen, die eine ebenmäßige Lamelle mit nur geringen von oben nach unten abändernden Breitenunterschieden besitzen, bei denen ferner die Lamellen des hinteren Zahnteils nicht $\mathrm{zu}$ sehr an Breite und Umriß von den vorderen verschieden sind. Den ersten Moment vor allen Dingen, das in sich wiederum mit der graduellen Ausbildung der Lateralpfeiler zusammenhängt, verdankt El. antiquus die meist gleichmäßig schmale, rechteckige und wenig ovale Kaufläche, die infolgedessen auch nur in geringem Maße den oben geschilderten Veränderungen im weiteren Verlauf der Abkauung unterworfen ist. Doch kommen auch hier sehr ovale Kauflächen vor. Für El. meridionalis könnte man eine relativ geringe Verschmälerung der Zähne nach hinten als charakteristisch hervorheben, wodurch das Vorherrschen ovaler Kauflächen bei dieser Art in den verschiedensten Abkauungsstadien erklärt ist. Allerdings ist die Art, wie in vielen anderen, so auch in diesem Merkmal großen Schwankungen unterworfen, so daß mehr rechteckige Kauflächen nicht zu den Seltenheiten gehören. Für El. trogontherii und seinen Deszendenten, das Mammut, gilt im höchsten Maße das Abändern der Kaufläche an M III nach der oben aufgestellten Regel. Bezüglich El. planifrons möchte man umgekehrt aus den überwiegend ovalen Kauflächen - des allerdings sehr geringen und deshalb vorsichtig auszuwertenden Materials - auf eine dem Verhalten des El. meridionalis sehr ähnliche resp. entsprechende geringe Verschmälerung der Zähne nach hinten schließen, welche als ein primitives Merkmal zu deuten ist. 
Mit diesen Erörterungen dürfte bewiesen sein, daß die Kauflächenform der M III als Bestimmungsmoment nur mit größter Vorsicht zu bewerten ist und stets unter Berücksichtigung des Abkauungsgrades eines Zahnes. Es dürfen nur die Kauflächen annähernd gleich weit abgekauter Zähne miteinander verglichen werden.

Die Kauflächenform des Dobermannsdorfer Fragments sagt uns überhaupt nichts bezüglich der Artzugehörigkeit des Stückes; sie ist von Schlesinger auch nicht herangezogen worden. Der Laaerberger Molar hat eine nahezu rechteckige Kaufläche, wie sie sowohl bei El. planifrons als El. meridionalis zu den weniger häufigen Typen bei letzten Unterkiefermolaren gehört, an letzten Oberkiefermolaren aber nicht selten ist; an Oberkiefermolaren erinnert der Laaerberger Zahn resp. die Figur überhaupt, besonders in Seitenansicht.

Die Form der Kaufläche kann also in Anbetracht der erheblichen Abänderungen und Schwankungen, denen sie im Laufe der Abkauung ausgesetzt ist, bei der Entscheidung, ob planifrons oder meridionalis vorliegt, nicht ins Gewicht fallen; sie ist indifferent besonders auch deshalb, weil Unterschiede in der Kauflächenform entsprechend abgekauter Zähne von El. planifrons und El. meridionalis nicht zu erweisen sind. Die Breite der beiden in Rede stehenden Zähne, $90 \mathrm{~mm}$ beim Laaerberger Zahn am 7. letzten, am Dobermannsdorfer am 4. letzten Joch, ist gleicherweise für die Artbestimmung belanglos.

\section{Der Längen-Lamellen-Quotient}

Der Quotient aus Länge und Lamellenzahl eines Zahnes gibt uns einen vergleichbaren Zahlenwert für die durchschnittliche Länge einer Schmelzfigur plus einen Zementintervall. Da bei ungefähr gleichbleibender Länge der einzelnen Molaren von älteren nach jüngeren Elephanten die Anzahl der Schmelzlamellen zunimmt, in unserem Bruch sich also der Divisor ständig vergrößert, der Quotient demnach verkleinert, so ist ein großer Längen-Lamellen-Quotient (späterhin abgekürzt L. L. Q.) charakteristisch für primitivere, ältere, ein kleiner L. L. Q. für fortgeschrittenere, jüngere Arten. Damit wird der L. L. Q. zu einem sehr wichtigen Bestimmungsmoment.

Bei den verschiedenen Zahnserien derselben Art ist der L. L. Q. beim M III am größten, wenig kleiner, oft aber ebenso groB am M II, um mit jedem vorhergehenden Zahn kleiner zu werden. Beim M M II beträgt er meist nur noch einhalb so viel als beim M III, beim M M III schließlich nur noch ein Drittel oder ein Viertel. Es erhellt daraus, 
daß man den L. L. Q. nur gleicher Zahnserien, also M III mit M III, M II mit M II usw. vergleichen darf, sobald Schlußfolgerungen für die Artzugehörigkeit eines Zahnes daraus gezogen werden sollen; ja, man muß sogar Ober- und Unterkieferzähne der gleichen Serie in diesem Merkmal auseinanderhalten, da bei einem Individium die Oberkieferzähne stets einen etwas kleineren L. L. Q. besitzen als die entsprechenden Zähne des Unterkiefers.

Besondere Verhältnisse sind für die M III, besonders des Unterkiefers zu berücksichtigen. In einer kürzlich erschienenen Arbeit ${ }^{1}$ ) habe ich ein Größenwachstum dieses Zahnes von älteren nach jüngeren Elephanten nachgewiesen. Durch diese Größenzunahme wird bis zu einem gewissen Grad die Zunahme der Lamellenzahl von älteren nach jüngeren Formen kompensiert, so daß beim M III das Kleinerwerden des L. L. Q. nicht in der gleichen gesetzmäBigen Weise, nicht in gleichem Tempo erfolgt wie bei den anderen Zähnen, die ihre wachsende Lamellenzahl nicht auf eine im gleichen Maße wachsende Zahnlänge verteilen können. Schon aus diesem Grunde sind die L. L. Q. der M III mit einiger Vorsicht zu gebrauchen. Es können jedenfalls - und mir sind eine ganze Anzahl solcher Fälle bekannt - hin und wieder letzte Unterkiefermolaren L. L. Q. aufweisen, die mit denen der nächst älteren Art übereinstimmen. Sind die letzten Molaren vollständig erhalten, so wird mit Hilfe der zahlreichen anderen Bestimmungsmomente leicht eine Korrektur, ein Erkennen des wirklichen Verhältnisses möglich sein. Neue Schwierigkeiten aber treten ein, sobald wir einen mehr oder weniger abgekanten Zahn vor uns haben.

Bei jedem letzten Unterkiefermolar zeigen die Schmelzscheiben eine radiale Anordnung, sie divergieren von oben nach unten, wie Fig. 5 an einem M III mand. von El. trogontherii von SüBenborn zeigt, und verteilen sich an der unteren Kontur der Zahnkronenbasis auf eine größere Fläche als im oberen Zahnteil. Das gilt ganz besonders von den Lamellen des hintersten Zahndrittels. Mit zunehmender Abkauung resp. Verlegung der Kaufläche aus der vorderen oberen Zahnpartie in die vordere untere und hintere obere Zahnpartie treten also die Lamellen auf der Kaufläche immer weiter auseinander, der Wert für eine Schmelzfigur plus ein Zementintervall, d. h. der L. L. Q. wird dauernd größer und erreicht schließlich seine größten Zahlen, wenn die Kaufläche nur noch im letzten Zahndrittel liegt.

1) W. Soergel, Die diluvialen Säugetiere von Baden. I. Teil. Mitteil. d. großh. badischen geol. Landesanstalt 1914 . 
Es ist besonders zu bemerken, daß die radiale Divergenz der Lamellen, die beim ganzen Zahn in Seitenansicht sehr deutiich hervortritt, bei fortschreitender Abkaung und Erniedrigung der Lamellen mehr und mehr zurücktritt resp. zurückzutreten scheint, daß schließlich die Lamellen des letzten Irittels eine lediglich parallele Stellung zu besitzen scheinen. Verdeckt man den oberen Zahnteil unserer Fig. 5 bis zu einem Schnitt, der in seiner Orientierung zum Zahn einer weit nach hinten verschobenen Kaufläche entspräche, so wird man sich leicht von dieser Tatsache überzengen. Stark abgekaute letzte Unterkiefermolaren täuschen also häufig eine mehr oder weniger parallele Stellung der Lamellen vor.

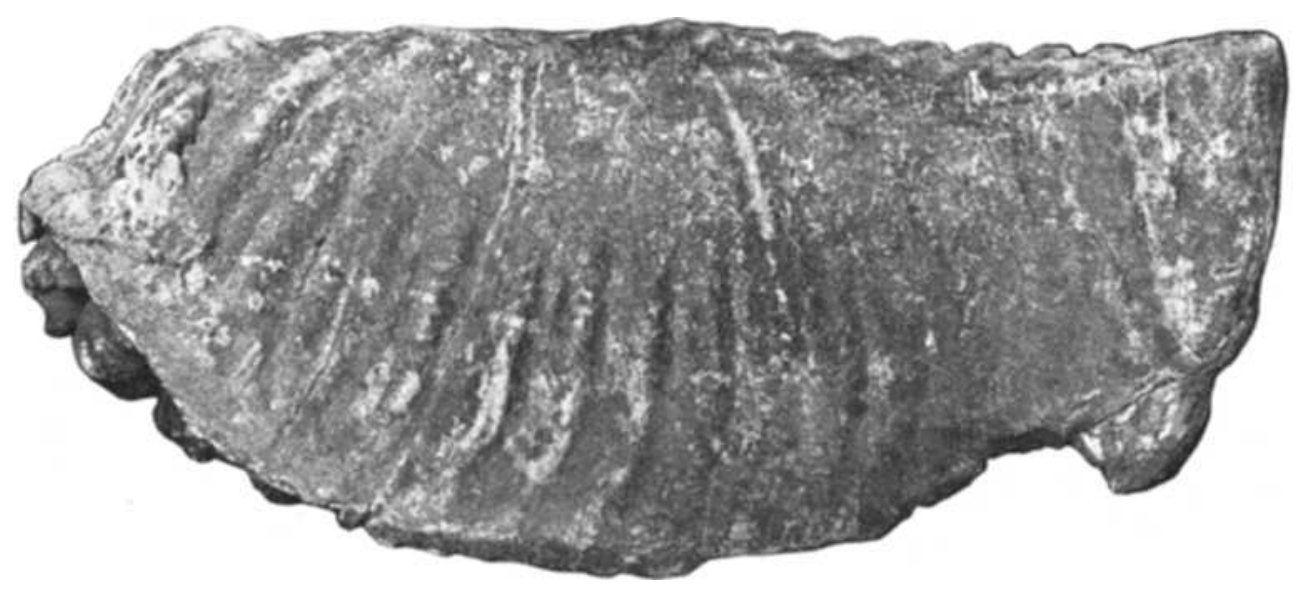

Fig. 5. Letzter Unterkiefermolar von Elephas trogontherii Pohl. aus den Kiesen von Süßenborn bei Weimar. $4 / 11$ natürl. Größe. Sammlung des Verfassers.

Der Zahn soll die radiale Divergenz der Lamellen von oben nach unten demonstrieren.

Auf die Abänderungen, die der L. L. Q. der M III mand. bei zunehmender Abkauung erleidet, habe ich a. a. O. S. 61, 62, 63 ausführlich hingewiesen. Ich habe dort gezeigt, daß der L. L. Q. eines M III mand. von El. trogontherii von Süßenborn, der beim ganzen Zahn 17,5 beträgt, auf 24,5 anwächst, wenn der vordere Talon und 9 Lamellen durch $\mathrm{Ab}$ kauung verschwunden sind und der Zahn nur noch eine Lamellenformel von $\infty 7 \mathrm{X}$ aufweist. Ich habe dort sehr ausführlich die Meridionalisartigen Molaren von Süßenborn diskutiert und gezeigt, daß es sich ausnahmslos um weitabgekaute letzte Unterkiefermolaren von El. trogontherii handelt. Die L. L. Q. dieser Zähne betragen je nach dem Grad der Abkauung: 16,$9 ; 17,8 ; 20,0 ; 20,2 ; 20,3 ; 21,9 ; 24,8 ; 28,1$. 
Für 2 letzte Unterkiefermolaren des gleichen Elephanten von Süßenborn ergaben sich je nach dem Stand der Abkauung folgende L. L. Q. Für den ganzen Zahn von X 16 X 320: $17=18,8$, bei einer Reduktion der Lamellenzahl auf $\infty 11 \times 252: 11,5=21,9$, bei einer Reduktion auf $\infty 10 \times 233: 10,5=22,2$ usw. langsam ansteigend. Für einen ganzen Zahn von X $21 \mathrm{X}$ ergibt sich $326: 21,5=14,8$, bei einer Reduktion auf $\infty 15 \mathrm{X} 279: 15,5=18,0$, auf $\infty 14 \mathrm{X} 266: 14,5=18,3$, auf $\infty 13 \times 253: 13,5=18,7$, auf $\infty 12 \times 238: 12,5=19,0$.

Diese sehr beträchtliche gesetzmäßige Abänderung der Größenwerte des L. L. Q. an letzten Unterkiefermolaren verlangt eine sehr kritische Wertung des L. L. Q. dieser Zahnserie als Bestimmungsmoment. Es dürfen in diesem Merkmal nur Zähne gleicher oder annähernd gleicher Abkaung verglichen werden. Die Nichtbeachtung dieser einfachen Regel hat schon sehr häufig zu Fehlbestimmungen geführt, lat abgekaute M III mand. des El. trogontherii in El. meridionalis, ähnliche Zähne des El. primigenius in El. trogontherii verwandelt. Soll ein stark abgekauter Zahn in dem L. L. Q. mit kompletten Zähnen verglichen werden, so kann man zur Korrektur eine Art Umrechnung heranziehen, wie ich sie im nächsten Abschnitt für den Zahn von Laaerberg benutzt habe.

Da stark abgekaute Zähne neben einem relativ hohen L. L. Q. noch häufig einen stärkeren Schmelz und breitere Zementintervalle besitzen können, als sie der speziellen Art eigentlich zukommen, so werden solche Zähne fälschlich mit schöner Regelmäßigkeit der geologisch nächstälteren Art zugeschrieben.

Von diesen Verhältnissen kann sich jeder an einem geringen Zahnmaterial von M III mand. irgend einer Elephantenart, ja, durch einige Messungen an ein em gut erhaltenen kompletten solchen Zahn überzeugen.

Für den Dobermannsdorfer Zahn, der nur noch $-5 \mathrm{X}$ führt, errechnet Schlesinger einen L. L. Q. von 25. Ein Zahn des El. trogontherii von Süßenborn in der ausgezeicheten Privatsammlung des Baurat Rebling zu Weimar zeigt hei $\infty 12 \mathrm{X}$ einen L. L. Q. von 24,8, ein Zahn mit $-4 \mathrm{X}$ der gleichen Art von Süßenborn im Museum zu Weimar einen L. L. Q. von 28,1. In der Größe des L. L. Q. unterscheidet sich der Zahn von Dobermannsdorf also nicht einmal von entsprechend abgekauten Zähnen des El. trogontherii, geschweige denn von El. meridionalis; das Dobermannsdorfer Zahnfragment kann nach diesen Merkmal jeder von beiden Arten zugehören.

Als direktes Bestimmungsmoment wird der L. L. Q. für diesen Zahn von Schlesinger nicht herangezogen. 
Für den Zahn von Laaerberg diskutiert Schlesinger den L. L. Q. etwas ausführlicher und kommt hinsichtlich der Verwendbarkeit dieses Merkmals zu ganz ähnlichen Resultaten wie ich in meiner Arbeit von 1912. Er schreibt

\section{S. 732:}

„Es ist daher am Platze, bei der Diskussion dieses Verhältnisses (des L. L. Q., Einfügung von Soergel) stets auf den Umstand Rücksicht zu nehmen, ob der Zahn vollständig, fast vollständig oder Bruchstück ist, ferner, ob vorn oder rückwärts Zement anhaftet und endlich, ob die Joche der Mittel- oder einer Randpartie entstammen."

Leider scheinen meine Ausführungen über das Anwachsen des L. L. Q. bei fortschreitender Abkauung auf S. 61-63 meiner Elephantenarbeit Schlesinger nicht überzeugt zu haben. Denn er hält den nach einer kleinen Korrektur errechneten L. L. Q. von 27,6 für den NormalL. L. Q. des ganzen intakten Zahnes und zieht zum Vergleich die L. L. Q. von 4 vollständigen letzten Unterkiefermolaren von El. planifrons und ein distales Bruchstück heran; gerade letztere weisen bekanntlich relativ sehr kleine L. L. Q. auf.

Vorerst einige Einwendungen gegen den von Schlesinger errechneten L. L. Q. von 27,6. Schlesinger schreibt:

„Der Längenlamellenquotient betrüge bei $233: 9=25,9 \mathrm{~mm}$; dieser Wert ist aber insofern korrekturbedürftig, als das vordere Schmelzjoch abschließt, über die ganze Länge also neun Lamellen, aber nur acht Zementintervalle verteilt sind.

Setzen wir das fehlende Intervall mit $15 \mathrm{~mm}$ an (durchschnittliche tatsächliche Entfernung zweier Joche), so erhalten wir 248: $9=27,6 \mathrm{~mm}$ als eigentlichen Quotienten".

So klar, wie Schlesinger behauptet, ist die Korrekturbedürftigkeit des ersten Wertes nun durchaus nicht. Schlesinger hat übersehen, daß bei jedem Zahn die Anzahl der Joche um 1 größer ist als die Anzahl der Zementintervalle, und es ist die Frage, ob man das Zementintervall hinter oder vor cinem Joch diesem zuzählen will, je nachdem bleibt das vorderste oder das hinterste Joch (Talon) ohne Zementintervall. Richtiger ist es wohl, die Abfolge von vorn beginnen zu lassen, wo auch die Abkauung beginnt, also den Zementintervall hinter dem distalen Talon diesem zuzuteilen usw. Jede Schmelzlamelle wäre dann mit dem hinter ihr folgenden Zementintervall zu einer Einheit zu verbinden, der proximale Talon wäre ohne Zementintervall. Die gelegentlich erhaltene, aber in 100 Fällen 99 mal fehlende Zementumkleidung des ganzen Zahnes braucht nicht in Rechnung 
gestellt zu werden. Bei einer solchen Auffassung der Sachlage wäre an dem Laaerberger Zahn zur Gewinnung des richtigen L. L. Q. nichts $\mathrm{zu}$ ergänzen oder doch nur recht wenig. Wir wollen ein übriges tum und ein halbes Zementintervall zur gemessenen Zahnlänge zuzählen und damit den L. L. Q. berechnen. Wir erhalten dann $240,5: 9=\mathbf{2 6 , 7}$. Mit diesem L. L. Q. werden wir in weiteren Abschnitten zu rechnen haben; aber auch dieser Wert darf bei Vergleichen nur vorsichtig und unter Beobachtung der oben auseinandergesetzten Regeln gebraucht und keinesfalls in der Weise, wie Schlesinger es tut, ausgewertet werden. „Schon aus den einfachsten Maßen“, meint er, "wie Lamellenzahl und Längenlamellenquotient erhellt die Identität des Stückes mit El. planifrons". In Wirklichkeit kann dem L. L. Q. eines so stark abgekauten Zahnes nur Bedeutung zugesprochen werden im Vergleich mit annähernd ebenso weit abgekauten Zähnen anderer Arten. Solche Zähne besitzen aber bei El. meridionalis ganz entsprechende Werte und können sogar bei El. trogontherii, allerdings in etwas stärker abgekautem Zustand, bis zu derartiger Höhe hinaufreichen.

Aus den angeführten Gründen kann der hohe L. L. Q. des stark abgekauten Zahnes von Laaerberg absolut nichts gegen die Zugehörigkeit des Stückes zu El. meridionalis — wir brauchen dabei nicht einmal an besonders primitive Vertreter der Art zu denken - und nichts für eine Zugehörigkeit zu El. planifrons beweisen.

\section{Die Lamellenformel und ihre Ergänzung}

Von geologisch älteren nach geologisch jüngeren Elephantenarten nimmt die Anzahl der Schmelzlamellen, die die einzelnen Zähne der verschiedenen Serien zusammensetzen, in sehr beträchtlichem Maße zu. Die Schwankungen, die in der Lamellenzahl jeder Zahnserie bei jeder Art auftreten, sind relativ gering und können den Wert der Lamellenzahl als Bestimmungsmoment nicht herabdricken. Voraussetzung bei einer Verwertung dieses Merkmals ist natürlich eine säuberliche Scheidung in geologisch ältere und jüngere Formen, auch dort, wo es sich scheinbar um eine "Art" handelt. Solange man z. B. alle Antiquusmolaren für geologisch gleichaltrig hielt, mußte man natürlich für die einzelnen Zähne recht große Schwankungen in der Lamellenzahl erhalten, die die Bedeutung dieses Merkmales in einem wenig günstigen Lichte erscheinen ließen. (Vergleiche Pohligs Arbeiten.) Seitdem wir aber wissen, daß El. antiquus ein sehr verschiedenes geologisches Alter innerhalb des Diluviums besitzen kann, seitdem wir die Zahnserien der verschieden- 
altrigen Fundorte getrennt miteinander vergleichen, löst sich die vorher große Schwankungsbreite in verschiedene kleinere, deutlich gegeneinander abgestufte auf. El. antiquus von Mauer hat bis auf die MM III stets niedrigere Lamellenzahlen als El. antiquus Taubach; vergleiche dazu die Tabellen meiner eben erschienenen Arbeit über die diluvialen Sängetiere Badens in den Mitteilungen der großh. bad. geol. Landesanstalt.

Wie bei allen anderen, so ist auch bei Benutzung dieses Merkmals zu beachten, daß die einzelnen Arten nicht durch scharfe Schnitte voneinander getrennt sind. Die höchste Lamellenzahl einer Zahnserie bei der geologisch älteren Art ist meist zugleich die tiefste der gleichen Zahnserie ihres direkten Deszendenten. Es handelt sich also um ein "fließendes" Merkmal, das häufig erst inı Verein mit anderen Merkmalen einen bestimmenden Wert erhält, für sich allein aber eine Entscheidung über die Artzugehörigkeit eines Zahnes nicht selten nur bedingt zuläßt.

Ihren vollen Wert hat die Lamellenzahl nur bei ganzen Molaren, bei denen kein Zweifel an der wirklichen Anzahl vorhandener Lamellen obwalten kann. Ist der Zahn vorn abgebrochen oder sind infolge Abkauung eine Anzahl Lamellen des vorderen Zahnteils verschwunden, so ist der Wert der ergänzten Lamellenzahl nur ein bedingter. Diese Ergänzungen bilden eines der schwierigsten Kapitel in der Dentition von Elephas, da sie eine sehr eingehende Vertrautheit mit dieser Materie voraussetzen, wie sie eben nur an Originalmaterial gewonnen werden kann. Die Gestaltung der Kaufläche gibt uns an sich gar keinen Anhaltspunkt für die Anzahl weggekanter Lamellen: sie macht durch das vorherrschende Oval ihres Lmrisses stets einen ganz intakten Eindruck und nur die Schmelzfiguren im vordersten Zahnteil, das Auftreten der sogenaunten Fusionserscheinungen in ihren mannigfaltigen Formen sagt dem Kundigen neben der Gestaltung der Wurzelpartie, daß er es mit einer rïckverlagerten Kaufläche, mit einer schon reduzierten Lamellenzahl zu tun hat.

Vielfach wird versucht, die Lamellenzahl zu ergänzen aus einem Durchschnittslängenwert der betreffenden Molireuserie, aus der Länge des in Rede stehenden Zahnfragments und dem an diesem Objekt berechneten L. L. Q. Hat man z. B. einen M III mand. mit einer Lamellenformel ron $\infty 11 \mathrm{X}$, einer Länge von $224 \mathrm{~mm}$ und einem L. L. Q. von 224: $11,5=19,4$, so verfährt man gewöhnlich folgendermaßen :

Die durchschnittliche Länge der M III mand. für Elephanten der meridionalis-trogontherii-Reihe des älteren Diluviums beträgt ca. $300 \mathrm{~mm}$. An unserem Zahnfragment hat eine Schmelzfigur +1 Zementintervall 
eine Länge von 19,4 mm. Der ganze Zahn hat dann soviel Lamellen besessen als 19,4 in 300 aufgeht; die Talons werden beim Endresultat ungefähr mit 1/2 Lamelle bewertet. Wir erhalten dann $300: 19,4=$ 15,4 Lamellen; berechnen wir jeden Talon mit 0,7, so ergibt sich schließlich die Lamellenformel X $14 \mathrm{X}$.

Diese Methode erscheint einfach und klar, arbeitet aber mit einem bedenklichen Fehler. Es wurde nämlich der L. L. Q. eines stark niedergekauten Zahnes als Durchschnitts-L. L. Q. eines ganzen Zahnes gesetzt. Wie wir im vorhergehenden Kapitel gesehen haben, ist der L. L.Q. eines ganzen Zahnes stets kleiner als derjenige eines stark abgekauten und verkürzten Zahnes. Der L. L. Q. muß also für unsere Rechnung verkleinert werden. Über das Maß dieser notwendigen Verkleinerung, das natürlich ganz exakt niemals festgestellt werden kann, wird der $A b$ kauungsgrad des betr. Zahnes entscheiden. Eine weiter hinten erläuterte Methode zeigt einen Weg, der zu befriedigenden Resultaten führt. Setzen wir in unserem Beispiel statt 19,4 uur 18,0, so würden wir schon eine ganze Lamelle mehr erhalten. Bei Zahnfragmenten, die nur noch 5-6 Lamellen enthalten, kann eine derartige Korrektur 4-6 Lamellen für den ganzen Zahı mehr herauskonstruieren. Wir sehen jedenfalls, daß eine Rechenmethode, wie die beispielsweise angeführte, die nötige Sicherheit vermissen läßt, daß die Resultate einer solchen Rechnung keineswegs ausschlaggebend sein können bei der Artbestimmung eines Zahnes.

Einen guten, aber nur zur Schätzung, nicht zur Berechnung brauchbaren Weg bietet die Gestaltung der Wurzelpartie. Je stärker die einzelnen Wurzeläste schon verschmolzen sind, je weiter die Bildung einer Dentinwand fortgeschritten ist, desto mehr Lamellen fehlen im vorderen Zahnteil. Soll die ergänzte Lamellenzahl ausschlaggebend sein für eine Artbestimmung, so ist mit dieser Methode allein natürlich kaum etwas anzufangen. Sie leistet aber im Verein mit der Anzahl noch nicht angekauter Lamellen gute Dienste dort, wo die Artbestimmung feststeht, wo also das mögliche Lamellen-Maximum und -Minimum für die Zahnserie bekannt ist. Je weniger ein solcher Zahn abgekaut ist, desto sicherer ist selbstverständlich die Lamellenergänzung vorzunehmen. Ist z. B. die vordere Wurzelpartie eben völlig verschwunden, so weiß man bestimmt, daß bei El. trogontherii am M III mand. 2-3 Lamellen und der distale Talon fehlen, bei El. primigenius $3-4$ Lamellen und der distale Talon usf.

Der Bestimmungswert des L.L.Q. kann nach alledem wohl ein recht großer sein bei vollständigen Zähnen, er schwindet 
aber in dem Maße, als im vorderen Zahnteil infolge Abkauung Lamellen verschwinden, und wird recht niedrig bei stark abgekauten Zähnen, die nur noch aus dem letzten Drittel eines Zahnes bestehen und nur in seltenen Fällen, bei sehr kritischer Wertung aller Momente eine einigermaßen verläßliche Ergänzung ermöglichen.

Für die Bestimmung des Zahnes von Dobermannsdorf ist eine rekonstruierte Lamellenzahl fast wertlos, da die Anzahl der noch vorhandenen Lamellen für eine derartige Ergänzung eine viel zu unsichere Basis abgibt. Scblesinger hat sie rechnerisch ergänzt und obwohl er anfangs den bedingten Wert dieser Rekonstruktion anerkennt, sie weiterhin doch positiv verwertet; siehe S. 103, Abs. 2, S. 109, Absatz 5 seiner 1. Arbeit.

Wir wollen uns hier kurz mit dem von Schlesinger zur Erschließung der Lamellenzahl eingeschlagenen Weg befassen. Schlesinger hat die oben skizzierte Methode angewendet und zwar mit dem Grundfehler dieser Methode: der Übertragung des zu großen L.L.Q. des Fragments auf den ganzen Zahn. Das muß an dem Dobermannsdorfer Fragment einen um so größeren Fehler in der Lamellenzahl bedingen, als das Fragment sehr stark abgekant ist und nur noch aus den letzten 5 Jochen besteht. Ein weiterer Irrtum in Schlesingers Berechnung liegt ferner darin, daß er die Breite des 3. Joches von hinten für die normale, größte Breite des ganzen Zahnes hält. Diese liegt aber nicht im hinteren Drittel, sonderm am Ende des vorderen Drittels eines M III mand. Die Breite des Fragments kann also nicht, wie Schlesinger meint, ein Grund sein, „die größte überhaupt bekannte Länge eines Archidiskodontenzahnes" nämlich $330 \mathrm{~mm}$ der Rechnung nicht zugrunde zu legen, weil dieser größte Zahn eine Breite von $109 \mathrm{~mm}$ besäße. Eine ähnliche Breite könnte unser Zahn wohl auch besessen haben. Vor allen Dingen aber hätte Schlesinger, wie gesagt, nicht einen L. L. Q. von 25, sondern höchstens von 22 (siehe folgende Seiten) in Rechnung setzen müssen, er hätte dann selbst bei der unbegründeten Längenannahme von nur $300 \mathrm{~mm}$ eine Lamellenzahl von X11 X $-\mathrm{X} 12 \mathrm{X}$ erhalten, die den wirklichen Verhältnissen auf jeden Fall näher kommt, wenn sie auch als Bestimmungsmoment nicht in Rechnung gesetzt werden darf.

Für den Laaerberger Zahn hat Schlesinger vermittels einer Plastelinergänzung gefunden, $d a ß$ am vorderen Zahnteil noch 2 Joche fehlen, die komplette Lamellenformel also $10 \mathrm{X}$ beträgt. . Dieser Plastelinergänzung des Zahnes auf seine ganze Länge, die nach Schlesinger 
„sehr zuverlässig“ zu konstruieren war, stehe ich sehr skeptisch gegenüber. Der Autor kann eine solche Ergänzung ja schließlich nur auf Grund seiner anatomischen Kenntnisse vom Bau des Zahnes, auf Grund seiner praktischen Erfahrungen verfertigt haben, die ich in diesem Falle nicht sonderlich hoch veranschlagen kann. Die Plastelinergänzung kann nur auf die gleichen irrtümlichen Ansichten über Wurzelbildung, Zahnhöhe usw. begründet sein, wie die Ausführungen des Autors in seiner 1. Arbeit. Eine Ergänzung des Stückes hätte vor allem die aus der Höhe des letzten Joches (nicht des Talons) zu erschließende ungefähre höchste Zahnhöhe zu verwerten. Recht gering scheint mir ferner die Größe von $270 \mathrm{~mm}$, zu der Schlesinger bei seiner Rekonstruktion gelangt.

Da die Erhaltung des Laaerberger Zahnes - siehe Fig. 6 und 7 eine vorzügliche ist, die Abkauung auch noch nicht bis zu jenem Grade vorgeschritten ist, wo eine Rekonstruktion zur Gewinnung neuer Bestimmungsmomente als völlig hoffnungslos bezeichnet werden muß, so mag hier eine kritische Rekonstruktion der Lamellenzahl aus den gegebenen Faktoren (wie sie Schlesingers Darstellung übermittelt) versucht werden. Wenn wir auch überzeugt sind, daß wir die wirklichen Verhältnisse nicht in dem Maße genau treffen werden, als es für eine uneingeschränkte Verwertung der Lamellenzahl als Bestimmungsmoment notwendig wäre, so wird unser Versuch doch erweisen, daß eine andere Lösung als die Schlesingersche bedeutend wahrscheinlicher ist.

Uns stehen zur Rekonstruktion folgende Daten zur Verfügung:

1. Die im 1. Abschnitt errechnete wahrscheinlich höchste Kronenhöhe.

2. Der Teil von der Kontur der unangekauten Molarenoberfläche, der den Talon mit den Spitzen des letzten und vorletzten Joches verbindet.

3. Die mögliche Maximalgröße des Zahnes von $330 \mathrm{~mm}$ auf Grund des gegenwärtig bekannten Materials.

4. Der L. L. Q. des Zahnfragments von 26,7, der zur Verwendung als Durchschnitts-L.L. Q. für den ganzen Zahn natürlich erheblich niedriger angesetzt werden muß.

5. Die Gestaltung der Wurzelpartie.

In unserem speziellen Fall erschwert sich die Rekonstruktion dadurch etwas, daß der Zahn von Schlesinger nicht in genau natürlicher Größe, sondern in einem für jeden Wert erst zu berechnenden Vielfachen davon dargestellt ist. Für das Endresultat ist das natürlich nebensächlich. 
Mit Hilfe unseres 1. und 2. Moments und unter Heranziehung der Tatsache, daß bei allen M III mand. die größte Zsinnhöhe am Ende des 1. Zahndrittels liegt, können wir rein konstruktiv den ungefähren Umriß des Zahnes in nicht angekautem Zustand erschließen.

Die Zahnkronenbasis jedes letzten Unterkiefermolaren bildet eine gekrümmte Fläche. Stellt man einen solchen Zahn, dem alle Wurzeln weggebrochen sind. auf die Zahnkronenbasis auf, so liegt der Auflagerungspunkt resp. Fläche ungefähr in der Mitte der Zahnlänge. Von der Stelle aus biegt sich die Kontur der Zahnkronenbasis nach hinten und nach vorn hoch. In dieser Stellung verläuft eine Linie, die die Spitzen der unangekauten Lamellen verbindet, fast horizontal, mit nur minimaler Steigung von den letzten Lamellen bis zur Mitte des vordersten Zahndrittels. Erst hinter den vordersten Lamellen macht sich ein stärkeres Aufbiegen bemerkbar. Wir orientieren unser Fragment nun so, daß die Verbindungslinie der Lamellenspitzen der letzten und vorletzten Lamelle (letztere etwas ergänzt) in ihrer Verlängerung eine fast horizontale, nur schwach ansteigende Linie bildet, verlängern die Kontur der Kronenbasis als schwache Kurve in dem Grade, wie es das erhaltene Stück angibt, und ziehen beide Linien nach vorn bis dahin, wo ihr Abstand $140 \mathrm{~mm}$, also die größte Kronenhöhe, beträgt. Hier liegt der Kulminationspunkt des Zahnes. Von hier biegt sich die untere Kontur erst allmählich, dann steil hoch, die obere geht noch ein kleines Stück in langsamer Steigung weiter, um sich erst an den vordersten Lamellen höher aufzubiegen. Ist der Kulminationspunkt eines Zahnes einmal annähernd bestimmt, so läßt sich der vorderste Zahnteil im entsprechenden Verhältnis leicht ergänzen, da der Kulminationspunkt stets am Anfang des 2., oder am Ende des 1. Zahndrittels liegt. Fig. 8 auf Seite 37 zeigt in Seitenansicht die Rekonstruktion des ganzen Zahnes in unangekautem Zustande; in der hinteren Hälfte ist die Kauflächenkontur des Originals eingezeichnet, dem anch die ganze hintere Wurzelpartie angehört.

Diese Rekonstruktion ergibt eine Gesamtlänge des Zahnes von $326 \mathrm{~mm}$. Wir wollen weiterhin mit nur $320 \mathrm{~mm}$ rechnen und damit den für die Schlesingersche Bestimmung als El. planifrons noch günstigsten Wert benutzen. Daß der Zahn eine große $270 \mathrm{~mm}$ übersteigende Länge besessen haben muß, geht indirekt schon aus der beträchtlichen Höhe des letzten Joches hervor. Und zwischen der Länge eines M III und der größten Zahnhöhe resp. der Höhe jedes Joches besteht bekanntlich ein gewisses, leicht zu errechnendes Verhältnis, das für jede Art natürlich spezifisch ist, innerhalb einer Art aber nur für 


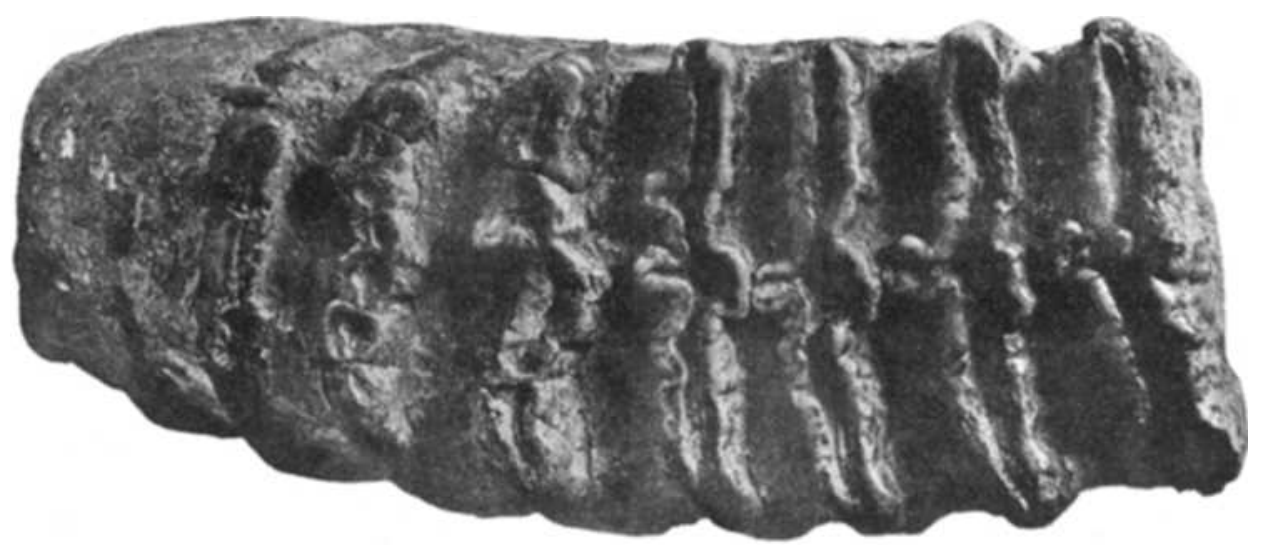

Fig. 6.

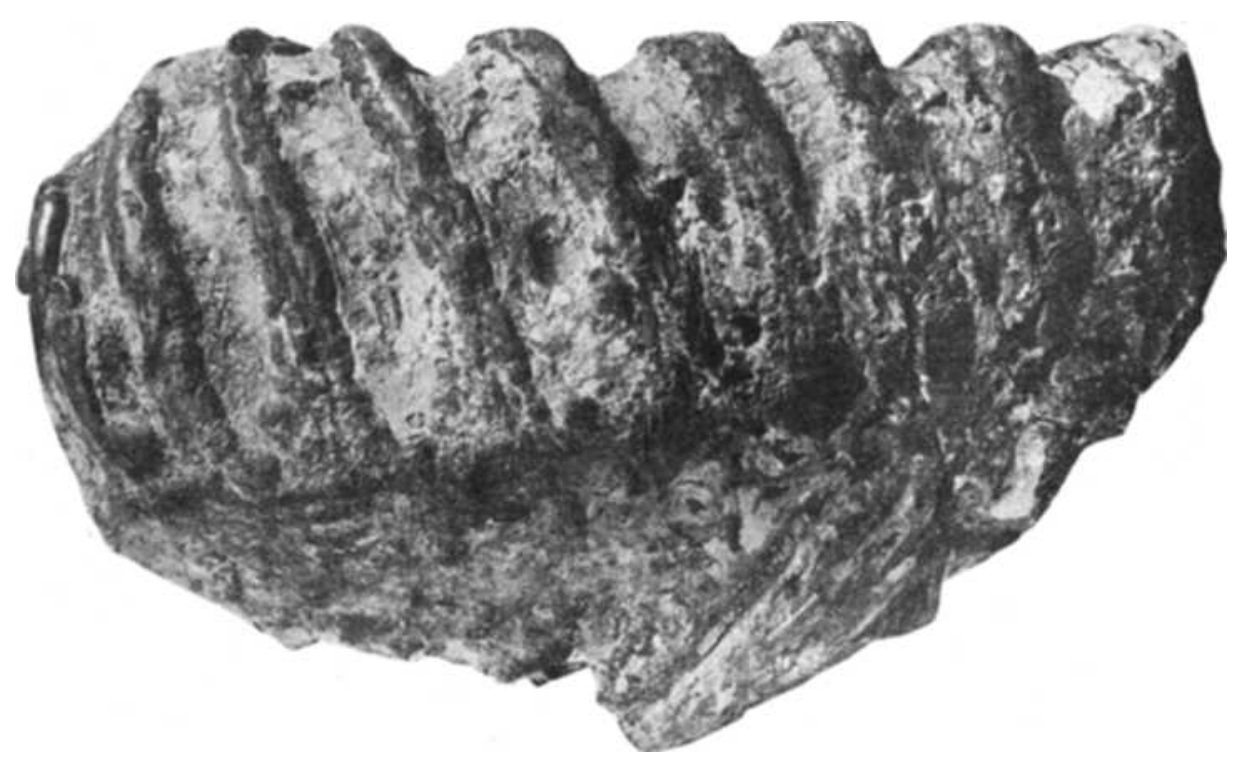

Fig. 7.

Fig. 6 und 7. Letzter Unterkiefermolar von Elephas meridionalis Nesti. Von oben und von der Seite. ca. $5 \%$ natürl. Größe.

Aus Schottern der Laaerbergterrasse bei der Ziegelei „Löwy" (früher "Rudolfsziegelöfen“) am Laaerberg, Wien XI. Original im Wiener Hofmuseum.

Nach G. Schlesinger, im Jahrb. d. K. K. Geol. Reichsanstalt 1913, Bd. 63, 4. Heit. Taf. XXVII und XXVIII. 
anormale, pathologische Zähne ungültig ist. Der Laaerberger Zahn ist nicht pathologisch.

Welche Anzahl von Schmelzlamellen und Zementintervallen verteilt sich nun auf die Zahnlänge von $320 \mathrm{~mm}$ ?

Die Länge für 1 Schmelzfigur plus 1 Zementintervall beträgt für unser Fragment $26,7 \mathrm{~mm}$. Damit können wir aus Gründen, die in $A b-$ schnitt 4 dargelegt sind, nicht für den ganzen Zahn rechnen. Um einen Maßstab zu erhalten, in welchem Grade wir die Zahl zu reduzieren haben, mögen folgende Berechnungen dienen.

Ein vollständiger M IlI mand. von El. trogontherii von Süßenborn mit einer Lamellenformel von X 17 X hat einen L.L.Q. von 17,5. Unser Laaerberger Zahn muß, mag er El. planifrons oder El. meridionalis angehören, eine Lamellenformel zwischen X $10 \mathrm{X}$ und $\mathrm{X} 13 \mathrm{X}$ besessen haben; er hat jetzt nur noch $8 \mathrm{X}$. Diese $8 \mathrm{X}$ können, je nachdem wir $\mathrm{X} 10 \mathrm{X}, \mathrm{X} 11 \mathrm{X}, \mathrm{X} 12 \mathrm{X}$ oder X $13 \mathrm{X}$ als Gesamtformel für den Laaerberger Zahn annehmen, beim Süßenborner, lamellenreicheren Zahn $11 \mathrm{X}$, $12 \mathrm{X}, 13 \mathrm{X}$ usw. entsprechen. Legen wir die jeder Abkaunng entsprechende Kaufläche durch den Süßenborner Zahn und berechnen den L. L. Q. für jedes Stadium, so erhalten wir in gleicher Reihenfolge wie oben 19,$6 ; 20,4 ; 21,5$; das ist also für jeden der $0,89-, 0,86-, 0,82$ ste Teil des L. L. Q. des ganzen Zahnes, nämlich 17,5! Wollen wir also aus einem L. L. Q. eines fortgeschritteneren Abkauungsstadiums den L. L. Q. des ganzen Zahnes berechnen, so müssen wir ersteren mit einer der erhaltenen Zahlen multiplizieren.

Für den unserem Laaerberg-Zahn entsprechenden L. L. Q. am Süßenborner Zahn erhalten wir den mittleren Multiplikanten 0,86.

Wie die oben dargestellte Methode ergibt, fußt dieser Wert letzten Endes auf der Annahme, daß die Gesamtlamellenzahl des Laaerberger Zahnes X $11 \mathrm{X}$ betrug. Mit dieser Annahme ist eine Artbestimmung keineswegs vorweggenommen, da sowohl El. planifrons als auch El. meridionalis diese Lamellenzahl am M III mand. aufweisen können. Ich werde aber auch weiterhin die erhaltenen Zahlenwerte stets möglichst zugunsten einer El. planifrons-Bestimmung auswerten, um der Schlesingerschen Auffassung, soweit es geht, entgegenzukommen.

An zwei weiteren M III mand. von Süßenborn berechnete ich für die derjenigen des Laaerberger Zahnes entsprechende Abkauung einen Multiplikator von 0,86 und 0,82 . Wir werden demnach 0,85 unbedenklich für die Umrechnung des Laaerberger Zahnes benutzen können.

Mit dieser Handhabe können wir aus dem L.L.Q. des Laaerberger Fragments den L. L. Q. des ehemaligen intakten Zahnes ungefähr be- 

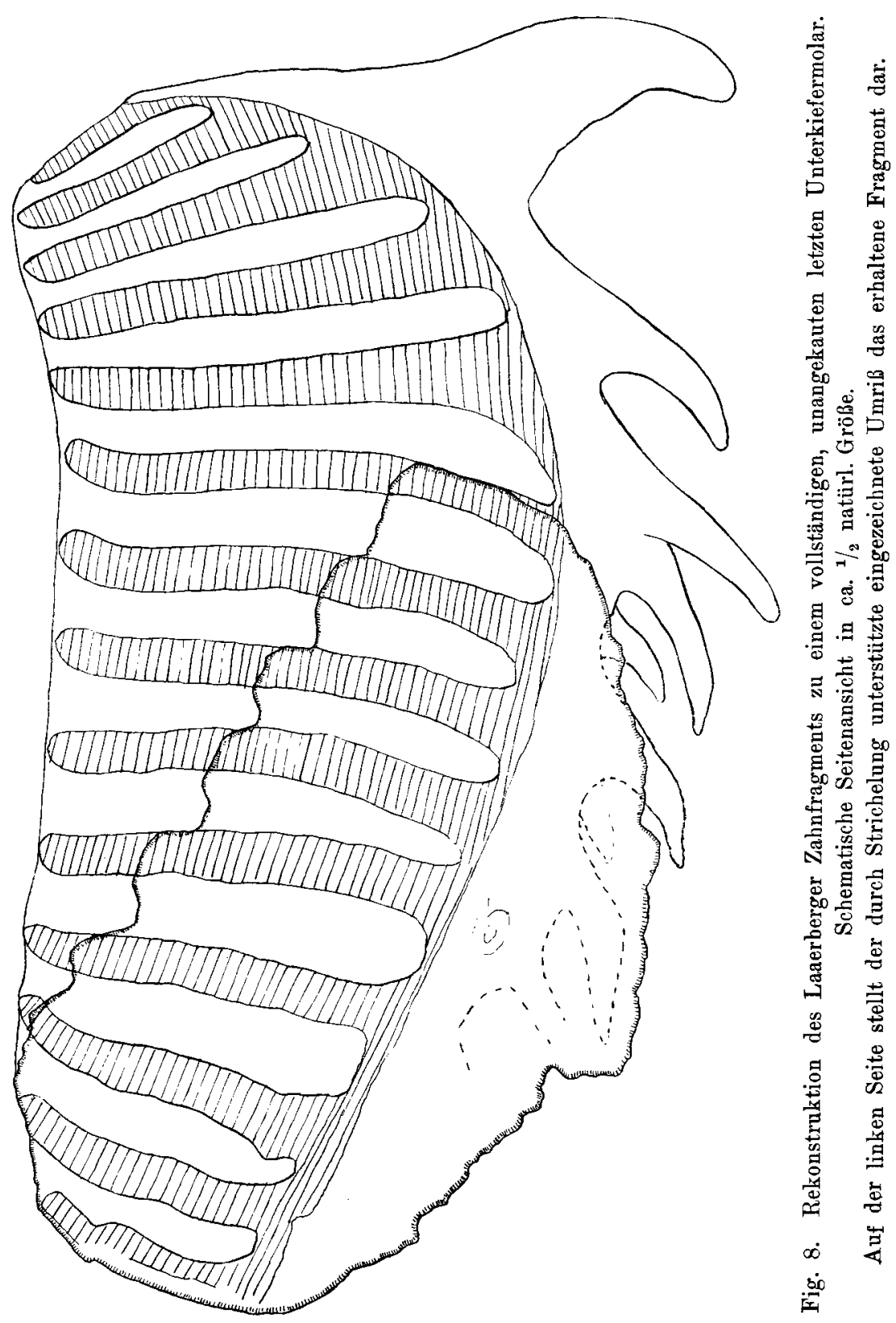
rechnen. Wir erhalten $26,7 \cdot 0,85=\mathbf{2 2 , 6}$. Um die Fehlerquellen, die zu ungunsten von El. planifrons sprechen könuten, auszuscheiden, wollen wir 23,0 annehmen. Die Anzahl der Schmelzlamellen plus Zementintervalle betrüge also für den ganzen Zabn $320: 23=\mathbf{1 3 , 9}$. Da nun die Anzahl der Schmelzlamellen — die beiden Talons mit eingerechnet stets um 1 größer ist als die Anzahl der Zementintervalle, die Talons aber außerdem jeder kürzer sind, als die echten Lamellen, so dürfen die beiden Talons mit nur 2/3 Lamellenwert berechnet werden; $d$. h. von 13,9 gehen 1,3 für beide Talons ab. Wir wollen aus wiederholt betonten Gründen 1,9 abrechnen und erhalten dann für den Zahn die Lamellenformel X12 X. Es fehlen dem erhaltenen Fragment also 4 Lamellen und der distale Talon. Zu einem ähnlichen Resultat führt uns die Betrachtung der Wurzelpartien, bei der die Bildung der Dentinwand für ein Fehlen von nur 2 Lamellen, wie Schlesinger annahm, zu weit fortgeschritten erscheint.

Wollten wir mit Schlesinger eine Rekonstruktion mit nur $270 \mathrm{~mm}$ Zahnlänge vornehmen, so würden wir entweder, wenn wir die Höhenverhältnisse richtig auswerten, einen merkwürdig klobigen, vorn stark abgestutzten Zahn, mit einem Wort, eine Anomalie erhalten; oder würden, weun wir, wie es Schlesinger tatsächlich tut, die Höhenverhältnisse der letzten Joche nicht richtig auswerten, einen zwar besser proportionierten, aber doch außerordentlich merkwürdigen Zahn erhalten. Der Zahn würde nämlich an allen Jochen von vorn nach hinten die gleiche Höhe besitzen, oder gar von hinten nach vorn niedriger werden - und zwar in unangekautem Zustand. Das ergäbe eine sehr merkwürdige, an M III mand. von Elephas noch in keinem Fall beobachtete Gestalt, die allerdings völlig dem entsprechen würde, was Schlesinger sich unter unangekauten letzten Unterkiefermolaren vorzustellen scheint. Berücksichtigen wir die Tatsachen der Erfahrung und verzichten darauf, bei Rekonstruktion des Zahnes zur Anomalie unsere Zuflucht zu nehmen, wozu kein Merkmal des Zahnfragments irgendwelche Veranlassung gibt, so ist eine Rekonstruktion nur in der von mir durchgeführten Weise möglich.

Schließlich muß ich noch darauf hinweisen, daß unser Resultat kein anderes geworden wäre, wenn wir den oben wiederholt erwähnten Multiplikanten zur Erlangung des normalen L. L. Q. nicht auf der Annahme basiert hätten, daß der Laaerberger Zahn $\mathrm{X} 11 \mathrm{X}$, sondern auf der, daß er nur X $10 \mathrm{X}$ besessen habe. In diesem letzteren Falle würden wir statt der in Rechnung gesetzten 23,0 etwas mehr, nämlich 23,2 als L. L. Q des ganzen Zahnes zu betrachten haben. Wir erhielten zum 
Schluß 13,8 statt 13,9 , also ebenfalls X 12 X. Hätten wir aber in unserer Hauptrechnung nicht fortwährend Korrekturen zugunsten einer Planifrons-Bestimmung angebracht, die ja eigentlich durch nichts begründet ist, so würden wir X $13 \mathrm{X}$ als Lamellenformel erhalten haben. Die Lamellenformel X 12 X hat also als Minimalwert zu gelten, sie stellt unsern Zahn durchaus in die Variationsbreite des El. meridionalis Nesti. Wegen der jeder Ergänzung anhaftenden Mängel will ich dieses Resultat aber nicht direkt zu einer Artbestimmung heranziehen, möchte aber doch betonen, daß irgend ein, geschweige denn ein zwingender Grund zur Bestimmung des Zahnes als El. planifrons auf diesem Wege keinesfalls gefunden werden kann.

Soweit die Zahnfragmente von Dobermannsdorf und Laaerberg Schlüsse auf die ehemalige vollständige Lamellenzahl zulassen, beweisen sie absolut nichts für eine Zugehörigkeit dieser Zähne zu El. planifrons, machen vielmehr eine Identität mit El. meridionalis in dem Maße wahrscheinlich, als es bei derartigen Lamellenrekonstruktionen überhaupt möglich ist.

\section{Der Verschmelzungstyp}

An anderer Stelle habe ich gezeigt, daß die Lamelle des Elephantenzahnes neben den in ihrer Anzahl bei einer Art, ja bei einem Zahn sehr schwankenden kleineren Abspaltungen, den Mammillen, in ihrem oberen Drittel durch zwei tiefgreifende Spalten in drei Teile geschieden ist, von denen ich den mittelsten als Mittelpfeiler, die beiden seitlichen als Seitenpfeiler bezeichnete. Wird eine Lamelle angekaut, so verschmelzen schnell die wenig tief greifenden Mammillen miteinander und es entsteht auf der Kaufläche eine aus 3 getrennten Teilen bestehende Schmelzfigur, die Einzelfigur des Mittelpfeilers und die der beiden Seitenpfeiler. In diesem Stadium der Abkauung, also kurz nach der Einschmelzung der Mammillen, bieten die Lamellen der verschiedenen Elephantenarten eine mehr oder weniger verschiedene Kauflächenansicht, die für die einzelnen Arten sehr charakteristisch ist. Man hat dieses Merkmal, das vor der Verschmelzung der Teilfiguren zu einer einheitlichen Figur zu beobachten ist, den Verschmelzungstyp genannt. Es lassen sich 3 Hauptarten des Verschmelzungstyps unterscheiden: Ist der Mittelpfeiler schwach, die Seitenpfeiler stark entwickelt, so haben wir auf der Kaufläche zwischen zwei länglichen, lamellaren seitlichen Figuren eine rundliche, annulare in der Mitte. Diesen Typ nennen wir lateral lamellar, median annular. Sind die 3 Pfeiler gleich stark entwickelt, so erhält man auf 
der Kaufläche 3 zwischen oval und lamellar schwankende Figuren. Überwiegt der Medianpfeiler an Stärke die seitlichen bedeutend, so werden die seitlichen Figuren annular, die mittleren lamellar erscheinen und damit eine lat. an. med. lam. Verschmelzung ergeben. Zwischen diesen Grundformen gibt es nuu alle möglichen Übergänge. Die Lateralpfeiler resp. ihre auf der Kaufläche erscheinenden Figuren sind natürlich äußerst selten bei einer Lamelle rechts wie links gleich ausgebildet, ja der eine ist ziemlich konstant bei allen Elephantenarten kleiner, schwächer als der andere. Bei Oberkieferzähnen ist der innere, bei Unterkieferzähnen der äußere schwächer entwickclt. Einer von beiden Lateralpfeilern steht dem Medianpfeiler an Stärke also in jedem Falle näher als der andere.

Die beiden Verschmelzungstypen, lat. an. med. lam. und lat. lam. med. an. bezeichnen natürlich nur 2 Extreme. Wo es wünschenswert ist, näher zu charakterisieren, geniigt diese Art der Bezeichnung nicht, genügt auch nicht die nähere Formbezeichnung jeder Teilfigur. Ich schlug deshalb vor, in solchen zweifelhaften Fällen, wo auch mit der Bezeichnung lat. lam. med. lam. nur wenig gewonnen ist, wenn irgend möglich die Mammillenzahl anzugeben, in die jeder Pfeiler zerlegt ist. Nur starke Lateralpfeiler tragen mehrere, zum mindesten 2 Mammillen, schwächere sind fast ausnahmslos nicht gespalten. Jedenfalls ist eine derartige Detaillierung geeignet, oft dort entscheidend einzugreifen, wo mit den nur relativen Begriffen annular und lamellar nicht viel anzufangen ist. Wo ist denn überhaupt die Grenze zwischen lat. an. med. lam. und lat. lam. med. lam. und lat. lam. med. an.? Solche Bestimmungen sind in zweifelhaften Fällen stets mehr oder weniger Ansichtssache der verschiedenen Autoren und Messungen, die die Benutzbarkeit dieses Merkmals natürlich wesentlich erhöhen würden, sind aus sogleich zu erörternden Gründen nur schwer durchführbar und können auch keine einheitliche Basis für alle Angaben bezüglich dieses Merkmals garantieren. Wollte man hier Maßvergleiche anstellen, so müßten alle Werte an Lamellen im gleichen Abkaungsstadium gewonnen sein. In der Tat bestimmt man ja auch heute schon, wo es möglich ist, den Verschmelzungstyp an der letzten Lamelle, die die 3 Teilfiguren zeigt. Die Sache bleibt aber insofern schwierig, als die einzelnen Pfeiler bis zu ihrer definitiven Verschmelzung zu einer Schmelzfigur eine mehr oder minder beträchtliche Größenverschiebung erleiden können. Diese hängt $a b$ von dem Umriß der Lamelle und vor allem vom Verlauf der beiden Hauptspalten. Fallen diese zum Medianpfeiler ein, so wird dieser und seine Kauflächenfigur bei fortschreitender Abkauung kleiner, die Seiten- 
pfeiler und ihre Figuren größer, fallen sie vom Medianpfeiler $a b$, umgekehrt, setzen beide parallel nach unten, so behält der Mittelpfeiler seine Größe, die Seitenpfeiler wachsen je nach dem Umriß der Lamelle. Diese Verhältnisse veranschaulicht nebenstehende Figur 9 a-9c. Der Einfallswinkel dieser Spalten ist bei den einzelnen Arten sehr schwankend, kann sogar bei den verschiedenen Lamellen eines Zahnes verschieden sein. Zumeist verhält es sich so, daß bei lat. an. med. lam.-Verschmelzung, also starkem Medianpfeiler, die Trennungspalten nach unten parallel verlaufen oder etwas konvergieren, so daß die Figur des Mittelpfeilers bis zur definitiven Einschmelzung in eine Figur etwas kleiner wird. Bei der Verschmelzung lat. lam. med. an. pflegen diese Spalten umgekehrt nach unten etwas zu divergieren, so daß die mediane Figur etwas zunimmt. Fin schwacher Medianpfeiler, der durch Divergieren der Spalten nach unten etwas anwächst, wird aber stets als ein schwacher Mittelpfeiler bezeichnet werden müssen, ein starker, der durch Konvergieren der Spalten etwas abnimmt, als ein starker. Das um so sicherer, als die Veränderungen niemals eine Lamelle aus dem Extrem des einen Verschmelzungstyps in das des anderen überführen. Es kann nur gelegentlich eine Umformung in den neutralen Mitteltyp lat. lam. (oval) med. lam. (oval) eintreten. Die Bezeichnungen schwach und stark für die einzelnen Pfeiler sind aber wesentlich aus der obersten Lamellenpartie hergeholt, wo die Unterschiede am augenfälligsten sind, wo Vergrößerungen und Reduktionen - wie sie im Laufe der Stammesgeschichte stattgefunden haben - sich am stärksten geltend machen. Es ist aus diesen Gründen wichtig, bei Vergleichen des Verschmelzungstyps gleich stark abgekaute Lamellen und, wo es angeht, wenig abgekaute zu vergleichen, in denen die 3 Teilfiguren sich eben aus der Fülle der Mammillen isoliert haben.

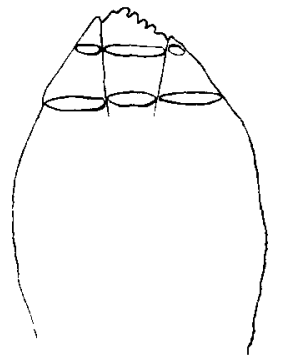

$9 \mathrm{a}$

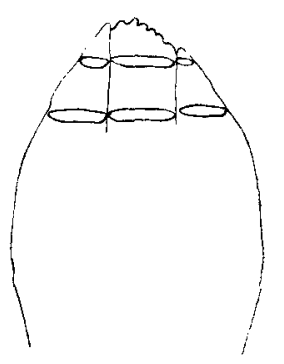

$9 \mathrm{~b}$

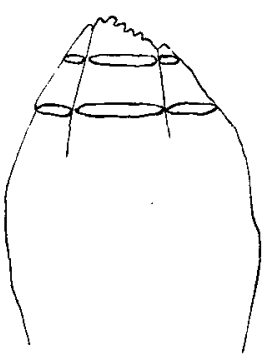

$9 \mathrm{c}$

Fig. $9 a-c$.

3 Lamellen mit versehieden einfallenden Hauptspaitęn und eingezeichnetem Verschmelzungstyp in 2 Abkauungsstadien. Die Darstellung veranschaulicht die Abänderungsfähigkeit des Verschmelzungstys bei fortschreitender Abkauung und seine Abhängigkeit vom Einfallen der beiden Hauptspalten. 
Die hohe Bedentung der Pfeilerausbildung in der Stammesgeschichte der Elephanten habe ich in verschiedenen Arbeiten gewürdigt. Schwachor Medianpfeiler und starke Lateralpfeiler sind das Primitivstadium, das El. planifrons, meridionalis, zum Teil hysudricus besitzen. Starker Medianpfeiler und schwache, reduzierte Lateralpfeiler bilden das fortgeschrittene Stadium, das am reinsten El. antiquus aufweist, nächst ihm El. africanus, das aber auch bei El. trogontherii, besonders den jüngeren Formen und El. primigenius, schließlich auch El. indicus vorherrschend ist. Von besonderem Interesse ist der von mir gefübrte Nachweis, daB zwei erloschene Stegodontenarten, Stegodon Airawana und St. trigonocephalus durch eine Dreipfeilerteilung der Joche einen wichtigen Schritt zur Elephaswerdung getan haben, daß dieser Fortschritt gerade in den Jochen des hinteren Zahnteils eintritt, vorn aber zu fehlen scheint.

Als Bestimmungsmoment ist der Verschmelzungstyp, wo es sich um Unterscheidnng primitiver und fortgeschrittener Formen handelt, sehr wertvoll. Besonders für die Unterscheidung des El. antiquus von zweifelhaften Molaren der Meridionalis-trogontherii-Reihe kann er häufig sehr gute Dienste tun, wenn auch gewöhnlich eine Reihe weiterer Merkmale vorhanden sind, die eine sichere Artbestimmung verbürgen. Die Hauptbedeutung des Merkmals liegt aber auf stammesgeschichtlichem Gebiet, wo es ein ausgezeichnetes Beispiel liefert für ein fließendes Merkmal, ein Mutationsmerkmal.

Ehe ich dieses Merkmal an den in Rede stehenden österreichischen Zähnen bespreche, sehe ich mich genötigt, auf eine Behauptung Schlesingers kurz einzugehen. Er schreibt S. 736 (II) "Soergel sagt (l. c. S. 9): „Einen schwachen Medianpfeiler zeigen die javanischen Stegodonten, von Elephanten in charakteristischer Ausprägung El. planifrons Falc. und El. meridionalis Nesti, in den meisten Fällen auch El. hysudricus."

Der Zahn von Laaerberg wollte zu dieser Behauptung ganz und gar nicht passen. Ich prüfte daher nach und fand wesentlich andere Verhältnisse vor, als sie Soergel behauptete."

Das Resultat dieser Prüfung, die an den Abbildungen Falconers vorgenommen wurde, hat Schlesinger in Gestalt einer Tabelle zusammengefaßt. Nach Fertigstellung dieser Arbeit hatte ich Gelegenheit, die "Prüfung“ Schlesingers nochmals zu überprüfen; ich gebe gern zu, daß er das Material im wesentlichen richtig gedeutet hat; es sind ihm dabei aber einige Zähne entgangen. Fig. 7 auf Taf. 11 in der Fauna antiqua Sivalensis läßt nach Schlesinger einen bestimmten Verschmelzungstyp nicht konstatieren. Ich sebe am letzten Joch einen sehr deutlichen schwachen Mittelpfeiler als annulare Figur, auf der 
Innenseite einen ungefähr ebenso starken, vielleicht etwas schwächeren Seitenpfeiler, als annulare Fignr nur verwischt erkennbar und schließlich unsicher zu erkennen ein sehr kräftiger Seitenpfeiler auf der Außenseite. Solchen Verschmelzungstyp nenne ich med. an. lat. lam. Nicht erwähnt ist bei Schlesinger Fig. 8 Taf. 14 mit typisch med. an. lat. lam.-Verschmelzung und die Zähne Taf. 14 Fig. 9 und 'Taf. 18 Fig. 1a, die einen Verschmelzungstypus nicht mehr erkennen lassen. Danach ergibt sich aus dem bei Falconer abgebildeten Zahnmaterial des El. planifrons für den Verschmelzungstypus dieser Art folgendes: Von 24 Zähnen zeigen

5 die Verschmelzung med. an. lat. lam.

$5 " \quad$ med. lam. lat. lam.

14 lassen den Verschmelzungstyp nicht konstatieren, sie fallen also für unsere Betrachtungen fort.

Wir haben oben gesehen, daß im Verlauf der Abkaung aus der Verschmelzung med. an. lat. lam. sehr wohl die Verschmelzung med. lam. lat. lam. hervorgehen kann, ja daß eine meist allerdings geringe Breitenzunahme des Mittelpfeilers nach unten bei allen Arten mit schwachem Mittelpfeiler stattfindet. Da aber ferner, wie wir oben sahen, eine Verschmelzung med. lam. lat. lam. gelegentlich aus dem anderen Extrem infolge Abkaung zum Vorscheine kommen kann, so ist eine Entscheidung, wohin in jedem Falle der Typus eigentlich gehöre, nur aus der Ausbildung der Lateralpfeiler abzuleiten. Und diese sind bei El. planifrons an allen Abbildungen sehr kräftig und zeigen dort, wo eine Beobachtung möglich ist, eine Spaltung in 2 Mammillen. Es kann demnach gar kein Zweifel sein darüber, wohin wir in unserem Falle den Verschmelzungstyp med. lam. lat. lam. zu stellen haben. Die ron Schlesinger an den Abbildungen Falconers gemachten Beobachtungen sprechen also durchaus für meine, früher auf Grund der gleichen Abbildıngen ausgesprochene Behauptung, daß El. planifrons einen schwachen Medianpfeiler besitze. Natürlich sind die Begriffe schwach und stark nur sehr relativer Art. Der Gegensatz und seine Größe werden aber sofort klar, wenn man den Lamellenbau des El. antiquus näher studiert und die gewaltige Entwicklung des Medianpfeilers bei reduzierten Seitenpfeilern beobachtet hat. Die Figuren 10 und 11 (Seite 44) veranschaulichen den Unterschied zwischen El. antiquus und El. meridionalis. Wenn Schlesinger schließlich S. 738 (II) schreibt: „Wir sehen demnach, daß der Fusionstypus von El. planifrons keineswegs als med. an. lat. lam. bezeichnet werden kann, sondern eine Mittelstellung einnimmt, innerhalb deren Varianten nach beiden Extremen hin, 
selbst in einem Zahn vereint, auftreten“, so kann er dieses Resultat kaum auf das diskutierte Molarenmaterial Falconers begründen. Und in der Tat zieht er zur Abrundung seines Ergebnisses die 3 österreichischen, nach allen vorhergehenden Erörterungen falsch bestimmten Zähne mit heran, die allerdings im Sinne Schlesingers Argumente sein könnten.

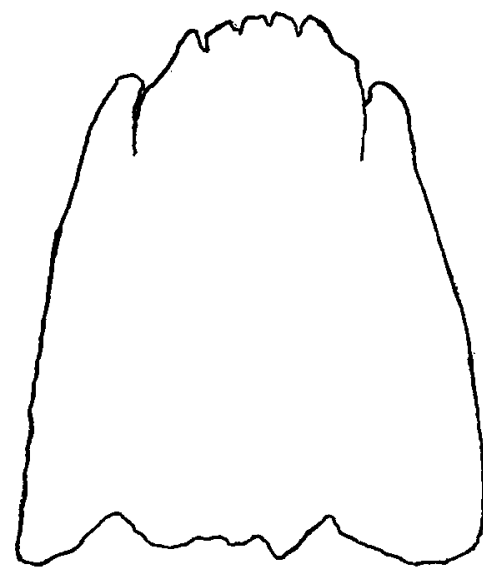

Fig. 10. Lamelle von Elephas antiquus Falc. von Taubach.

(Nach Soergel, Palaeontographica, 1912.) Zeigt den auberordentlich kräftigen Mittelpfeiler mit seinen Mammillen und die stark reduzierten Seitenpfeiler.

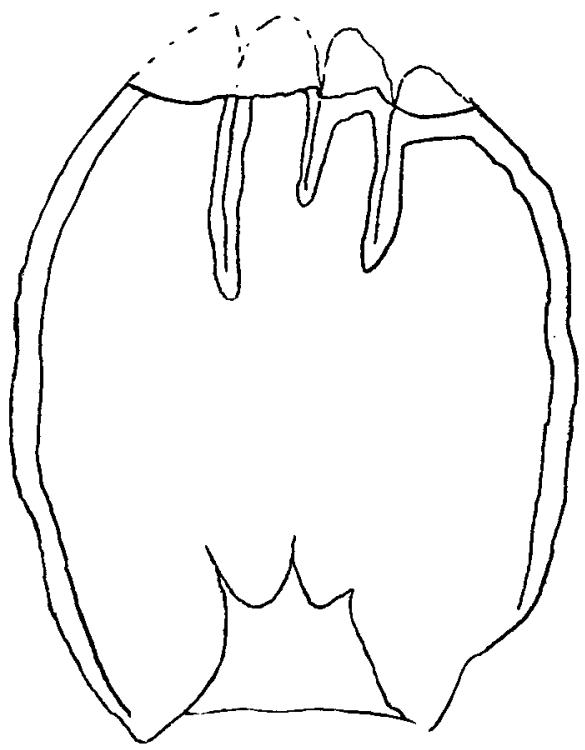

Fig. 11. Lamellen von Elephas meridionalis aus dem Val d'Arno.

(Nach Soergel, Palaeontographica, 1912.)

Zeigt den schwachen Mittelpfeiler neben sehr kräftigen Seitenpfeilern.

Was den von Schlesinger erwähnten Zahn anbetrifft, der „Varianten nach beiden Extremen hin" vereint, so ist darüber folgendes zu sagen. Der Zahn läßt den Verschmelzungstyp an 4 Lamellen erkennen und zwar einmal med. an. lat. lam., zweimal med. lam. lat. lam. und einmal med. lam. lat. an. Ist ein Zahn so angekaut, daß er an mehreren Lamellen den Verschmelzungstypus erkennen lält, so ist es bei allen Elephantenarten die Regel, daß er an jeder Lamelle etwas anders ist, wie an der folgenden, entsprechend der verschiedenen $\mathrm{Ab}$ kauung. In solchen Fällen zeigt sich aber von der letzten unverschmolzenen eine allmähliche Steigerung bis zur letzten Lamelle, eine 
Verschmelzung lat. lam. med. lam. geht allmählich in lat. an. med. lam. über usw. Die Reihenfolge der verschiedenen Verschmelzungstypen an dem Planifronszahn ist keine solche, daß die Verschiedenheiten auf verschieden starke Abkauung zurückgeführt werden könnten, es kann sich hier nur um. Schwankungen im Bau der oberen Lamellenpartie handeln. Solche Schwankungen kommen nun besonders an Zahnende - und darum handelt es sich ja auch bei diesem Zahn -- bei allen Elephantenarten nicht selten vor. Es erscheint deshalb keineswegs verwunderlich, daß sich am letzten Zahnende einmal ein „fließendes" Merkmal plötzlich auf einer Höhe findet, wie wir es erst bei jüngeren Nachkommen der Art anzutreffen gewohnt sind. Irgendwelche Schlüsse aus solchen ganz vereinzelten Vorkommen auf die allgemeine Höhe des in Rede stehenden Merkmals bei der betreffenden Art wird man daraus selbstverständlich nicht ableiten dürfen. Durch das ganze übrige Material ist dieses Merkmal in seiner für eben diese Art charakteristischen Entwickelungshöhe doch unverrückbar festgestellt, so daß man den Fall als eine in der eingeschlagenen Entwickelungsrichtung liegende Absonderlichkeit zu betrachten hat. Daß bei Proboszidierzïhnen gerade die Joche des hinteren Zahnteils manchen Fortschritt zuerst und am deutlichsten zu realisieren scheinen, habe ich an anderer Stelle schon betont.

Über den Verschmelzungstyp der österreichischen Zähne ist schließlich folgendes zu sagen. Der Verschmelzungstyp des Dobermannsdorfer Molaren ist lat. lam. med. lam., in einer Form, wie sie sowohl El. planifrons als El. meridionalis, als schließlich im letzten Zahnviertel häufig El. trogontherii aufweist. Es kann dieses Merkmal für die Bestimmung des Zahnes keinesfalls entscheidend sein.

Der Zahn von Laaerberg - siehe Fig. 6 - zeigt am 4. Joch von hinten am klarsten einen Verschmelzungstyp, allerdings schon an der Basis der Trennungsspalten, da die direkt vorhergehende Lamelle schon völlig verschmolzen ist. Wir sehen eine lat. an. med. lam.-Verschmelzung, die aber für diesen 'Typus keineswegs sehr ausgesprochen ist, wie Schlesinger meint. Wer Zähne von El. antiquus kennt, würde sogleich bemerken, daß der Laaerberger Zahn einen unteren Grad dieses Verschmelzungstyps aufweist. Nach Schlesinger ist jede Lateralfigur $2 / 3$ der medianen, also für diesen Verschmelzungstyp recht viel; zudem hat jeder Lateralpfeiler aus 2 Mammillen bestanden. Über die nach hinten folgenden Lamellen macht Schlesinger leider keine Angaben und aus der Abbildung ist die Pfeilerentwickelung nicht mit wünschenswerter Sicherheit zu erkennen. Es erscheint aber der Mittelpfeiler resp. seine Kauflächenfigur in dem geringeren Abkauungsstadium wesentlich schwächer zu sein, 
was in Anbetracht der Tatsache, daß die Schmelzfigur der vorhergehenden Lamelle einen Schnitt an der Spaltungsbasis darstellt, durchaus wahrscheinlich ist.

Einen Verschmelzungstypus wie am 4. letzten Joch des Laaerberger Zahnes sah ich verschiedentlich an Originalmaterial. von El. meridionalis, kenne ihn aber nach Falconers Abbildungen nicht an El. planifrons, für den der Mittelpfeiler, selbst als Basisschnitt etwas zu kräftig erscheint. Doch hier muß mit allerlei kleinen Schwankungen gerechnet werden.

Als sicher kann man jedenfalls behaupten, daB der Verschmelzungstyp des Laaerberger Zahnes nicht ausschlaggebend sein kann für eine Bestimmung als El. planifrons oder als El. meridionalis, daß aber für El. meridionalis Fälle ganz entsprechender Verschmelzung bekannt sind, was für El. planifrons - abgesehen von einer oben als aberrant ckarakterisierten Lamelle eines Zahnes - nicht zutrifft.

\section{Die Eigenschaften des Schmelzes}

(Stärke und Fältelung)

Die Schmelzstärke ist ein zur Unterscheidung von verschiedenen Elephantenarten mit großer Vorsicht zu brauchendes Merkmal. Wohl gilt der Satz, daß geologisch ältere Arten dickeren, geologisch jüngere Arten dünneren Schmelz besitzen, doch ist das Merkmal nicht unbeträchtlichen Schwankungen, vor allem an einem Zahn im Verlauf der Abkauung einer solchen Abänderung unterworfen, daß die Schmelzstärke, besonders an stark abgekauten Zähnen, nur im Verein mit allen anderen Merkmalen und unter genauester Berücksichtigung all der Nebenumstände, die die Schmelzstärke auf der Kaufläche beeinflussen können, verwendet werden darf. Mit dem jeweiligen Grad der Abkauung einer Lamelle ändert sich die auf der Kaufläche meßbare Schmelzstärke in folgender Weise: „Die Schmelzstärke ist am bedeutendsten in der oberen Partie der Lamellen. Von hier nimmt sie wenig ab bis zur definitiven Verschmelzung der drei Pfeiler. Im mittleren und oberen Teil des unteren Drittels bleibt sie zumeist gleich oder wird wieder etwas stärker, um dann basal allmählich ganz auszudünnen" (Soergel 1912). Den stärksten Zahnschmelz besitzen bei ein und derselben Art stets die letzten Molaren, bei den vorhergehenden Zähnen ist er in dem Maße dünner, als die Zähne kleiner und graziler gebaut sind. Besonders starken Schmelz weisen die Lamellen des hinteren Zahndrittels von letzten Unterkiefermolaren auf. Stark abgekaute Zähne dieser Serie werden deshalb stets 
sehr kräftigen Schmelz zeigen, sie dürfen in diesem Merkmal deshalb nicht ohne weiteres mit weniger abgekauten Zähnen derselben oder einen anderer Art verglichen werden. Häufig wird aber gerade bei stark abgekauten M III mand. eine besondere Schmelzstärke auf der Kaufläche vorgetäuscht dadurch, daß die Kaufläche die Lamellen nicht rechtwinklig, sondern mehr oder weniger schief schneidet. Derartige Zähne, bei denen ja auch das Zementintervall infolge des schiefen Schnittes auf der Kaufläche weit größer erscheint, als es in Wirklichkeit ist, besitzen deshalb oft ein besonders primitives Aussehen und werden von weniger geübten gern fälschlich einer geologisch älteren Art zugeteilt, als der sie in Wahrheit angehören.

Vor allem eine Funktion der Schmelzstärke ist das häufig beobachtete mauerartige Überragen der Schmelzfiguren über die Kaufläche. Diese Erscheinung trifft man nur bei Elephantenarten, die einen starken Zahnschmelz besitzen; ein solcher nämlich bedingt beim Kauprozeß eine beträchtlich langsamere Abnutzung der Schmelzlamelle als des Zements, der übrigens auch vom Speichel nicht unbeträchtlich angegriffen wird. Das Vorkommen solcher Lamellenüberragungen ist deshalb beschränkt:

1. auf primitive Elephanten mit starkem Zahnschmelz, wie EI. africanus, El. planifrons, El. meridionalis und ältere Formen des El. antiquus und El. trogontherii.

2. auf stärker abgekaute letzte Mandibel- und Maxillenmolaren von El. antiquus und El. trogontherii, die in den hinteren Lamellen die gleiche Schmelzstärke wie die drei oben zuerst genannten Arten nicht selten erreichen; El. primigenius zeigt die Lamellenüberragung äußerst selten.

Ein Artmerkmal ist diese Erscheinung also nicht, oder doch höchstens erst in zweiter Linie, denn auch bei den primitiveren Elephanten ist es nicht an allen Zähnen, nicht einmal an allen letzten Molaren vorhanden.

Die Art und Weise der Schmelzfältelung ist selbst bei einer Art sehr großen. Schwankungen unterworfen. Im allgemeinen kann man aber sagen, daß sie in der Lamelle von oben nach unten zunimmt. Bei El. antiquus beobachtet man die stärkste Fältelung meist im 2. und 3. Viertel der Lamellenhöhe. Bei El. trogontherii mehr im 3. und letzten (tiefsten) Viertel. Doch sind, wie gesagt, diese Verhältnisse bei allen Elephanten dermaßen der Variation unterworfen, daß sie als Bestimmungsmoment selbst nur als Teilmerkmale kaum in Betracht kommen. Bei Besprechung der Schmelzfiguren werden wir nochmals darauf zurückkommen. 
Die Schmelzstärke ist bei beiden österreichischen Zähnen keine außergewöhnliche, die unbedingt auf eine Zugehörigkeit der Zähne zu El. planifrons hinweisen müßte. Für den Dobbermannsdorfer Zahn, von dem ich Dank dem Entgegenkommen des Herrn Schlesinger einen sehr schönen Gipsabguß erwerben konnte, gibt Schlesinger selbst keine Maße an; die Schmelzstärke stimmt mit entsprechend abgekauten Zähnen von El. trogontherii gut überein und geht über das Maß von normal abgekauten Zähnen des El. meridionalis nicht hinaus. Das gleiche gilt von dem Zahn von Laaerberg, für den Schlesinger angibt: „Die Dicke des Schmelzbleches beträgt in der Regel $4 \mathrm{~mm}$, erreicht aber an vielen Stellen $5 \mathrm{~mm}$, an einzelnen sogar das ungewöhnliche Maß von $6 \mathrm{~mm}$ ". In diesen Grenzen bewegen sich die Schmelzstärken entsprechend abgekauter Zähne von El. meridionalis immer, solche von El. trogontherii und El. antiquus meistens.

Das Überragen der Joche über die Zementbasis beträgt bei dem Dobermannsdorfer Zahn bis 15, beim Laaerberger bis $12 \mathrm{~mm}$. In ähnlichen und höheren Werten bewegen sich solche Überragungen bei entsprechend abgekauten Zähnen des El. meridionalis - natürlich nicht bei allen; wenn Schlesinger S. 101 bezüglich der Rautenförmigkeit der Joche schreibt: „Die typischen Meridionaliszähne dagegen sind gerade durch das Gegenteil gekennzeichnet", so dürfte er diese Kenntnis lediglich aus den Abbildungen der Literatur geschöpft haben, die bis dato nur die guten großen, nicht aber die fragmentären und stark abgekauten Stücke abbildete. Die Durchsicht eines größeren Molarenmaterials dürfte Herrn Schlesinger in seiner Ansicht schnell wankend machen. In ähnlichem Ausmaße, wie bei den beiden österreichischen Zähnen kommen übrigens bei stark abgekauten M III von El. trogontherii nicht selten solche rautenförmigen Überragungen vor. Ein stark abgekauter M III mand. meiner Sammlung aus Süßenborn Lamellenformel - $10 \mathrm{X}$, alle Lamellen angekant - zeigt solche Überragungen bis maximal $15 \mathrm{~mm}$.

Es ergibt sich, daß die Schmelzstärke und die rautenförmige Überragung der Joche weder den Zahn von Dobermannsdorf noch den von Laaerberg von entsprechend abgekauten Zähnen des El, meridionalis unterscheiden, ja, daß diese beiden Merkmale allein nicht einmal eine Trennung von El. trogontherii nötig machen würden. Für eine Bestimmung der Zähne als El. planifrons können diese Merkmale nichts beweisen. 


\section{Die Schmelzfigur}

Durch Verschmelzung der medianen mit den beiden lateralen Teilfiguren entsteht auf der Kaufläche die Schmelzfigur. Nach ihrem Umriß kann man sie in zwei Hauptgruppen aufteilen.

\section{Die rhombische Schmelzfigur}

Sie ist charakteristisch für El. antiquus, namadicus und africanus und besonders ausgezeichnet durch das langsam gleichmäßige Anschwellen der Figur von beiden Seiten nach der Mitte zu. Die dadurch bedingte Rhombenform wird häufig unterstützt durch feinere und gröbere Zipfel, die in der Mediane des Zahnes aus der vorderen und hinteren oder auch nur aus einer der beiden Schmelzwände einer Schmelzfigur herausspringen.

\section{Dio uuregelmäßig rechteckige oder bandförmige Schmelzfigur}

Als Grundtypus möchte ich eine Figur bezeichnen, die neben gleichmäßig bandförmigen Seitenteilen ein breiteres Mittelstück besitzt, das nach beiden Seiten hin durch Einschnürung der Figur etwas abgeschlossen ist und aus der Flucht der ganzen Figur meist recht unvermittelt herausspringt. Sehr charakteristisch für diese Gruppe ist das scharfe Absetzen der seitlichen T'eile am Mittelstück, das dadurch bedingt ist, daß die beiden Hauptspalten der Lamelle nach ihrer Einschmelzung sich als Depression noch tief in die Lamelle hinunter fortsetzen und häufig erst im letzten, tiefsten Drittel auslaufen. Dann erst macht dieser deutlich dreiteilige Bau der Schmelzfigur einer gleichmäßigen Form von häufig rechteckigem Charakter Platz. Sehr schwankend ist die Gestaltung des mittleren Teils, der Grad, in dem er aus dem Verlauf der Seitenteile nach vorn oder hinten oder nach beiden Seiten heraustritt. Bei geologisch jüngeren Formen ist er mehr in den Verband der ganzen Figur eingewachsen, bei geologisch älteren aber meist sehr markant von den Seitenteilen abgesetzt.

Diesen zweiten Typus der Schmelzfigur finden wir bei El. planifrons, El. meridionalis, El. trogontherii und El. indicus, bei letzterem, wie überhaupt bei allen Hysudricusabkömmlingen allerdings sehr selten typisch, sondern meist in einer Art Zwischenstellung zwischen beiden Typen.

Wie die meisten Merkmale des Elephantenzahnes, so ist auch die Schmelzfigur lediglich eine Funktion der Lamelle und zeigt dementsprechend alle Abänderungen, die eine Lamelle von oben nach unten 
durchläuft, als Projektion auf der Kaufläche. Hier verdient zuerst die von mir 1912 als "Schmelzbrücke" bezeichnete Bildung am basalen Teil der Lamellen eine kurze Besprechung. Das Dentin aller Lamellen kommuniziert im unteren Zahnteil miteinander durch eine in der Mediane der Lamellen verlaufende Spalte. Diese Spalte ist, einem unterirdischen Gang vergleichbar, vollständig eingedeckt mit Schmelz und führt durch die Zementintervalle hindurch von Lamelle zu Lamelle. Werden die Lamellen bis zur Schmelzbrücke abgekaut, so zeigen sich auf der Kaufläche die unter dem Ausdruck „Fusion“ bekannten Verschmelzungen der einzelnen Schmelzfiguren, die zuerst durch einen schmalen "Kanal“ in der Mitte der Kaufläche miteinander in Verbindung treten. Für die Schmelzfigur ist aber besonders wichtig, daß von dieser "Schmelzbrücke" aus, und zwar besonders auf der Lamellenrückseite, ein Schmelzwulst von individuell wechselnder Stärke und Höhe an der Lamelle hochzieht und oben, wenigstens bei den geologisch jüngeren Arten in der Lamelle verschwindet. Dieser Wulst ist häufig von einem System feinerer Wülste begleitet, die aber stets auf den Mittelpfeiler beschränkt bleiben. Auf der Kaufläche macht sich dieser Wulst geltend durch mehr oder weniger starke Falten und Auftreibungen des Mittelstückes der Schmelzfigur. Bei Besprechung der Schmelzbrücke 1912 S. 10 und 11 habe ich als Analogon auf die mediangespaltenen Zähne der Mastodonten und gewisser Stegodonten hingewiesen. Eine viel größere Bedeutung in ähnlichem Sinne möchte ich heute diesem Schmelzwulst beilegen. Es ist sehr auffallend, daß dieser Wulst bei geologisch älteren Arten viel kräftiger ist, als bei geologisch jüngeren, daß er bei ihnen häufig im oberen Teil der Lamelle selbständig wird, sich ablöst nnd als EinzelDigitelle bei kaum angekauten Lamellen hinter dem Mittelpfeiler im Zementintervall steht. Die Abkauung verschmilzt ihn allerdings schnell mit der Hauptschmelzfigur, an der er dann eine starke Auszackung oder Ausbuchtung des Mittelstückes hervorruft. Das gilt sowohl für El. planifrons und El. meridionalis als ganz besonders für El. africanus, wo ich derartige Verhältnisse äußerst verbreitet fand. Es liegt nahe, das viel schwächere Auftreten dieser Erscheinung bei geologisch jüngeren Elephanten als die Folge einer Reduktion zu erklären, für die Vorfahren des El. planifrons und El. africanus aber eine noch stärkere Ausbildung dieser Besonderheit, eine noch ausgesprochenere Isolierung dieses "Wulstes" von der Lamelle anzunehmen. Man könnte diesen Schmelzwulst direkt als einen der Lamelle erst im Laufe der Entwickelung eingeschmolzenen Sonderpfeiler auffassen, der dem Sperrhöcker einiger Mastodonten durchaus gleichzusetzen wäre. Eine solche Annahme könnte eine weitere 
Stütze darin finden, daß bei den älteren Elephanten, ja sogar noch beim El. antiquus von Mauer, dieser Wulst resp. die Auszackung am Mittelstück der Schmelzfigur ganz vornehmlich von der hinteren Schmelzwand ausgeht, also nur auf einer Seite der Lamelle entwickelt ist. Je nach dem wohl auch individuell schwankenden Grad der Einschmelzung eines solchen Wulstes, kann schließlich zur hinteren Auszackung auch noch eine vordere treten; die vordere allein, bei glattem Verlauf der Hinterwand gehört jedenfalls zu den Seltenheiten. Über den Mechanismus einer solchen Einschmelzung und alle weiteren sich anknüpfenden Detailfragen können natürlich nur eingehende studien an sehr reichem Material aller Zahnserien in allen Entwicklnngsstadien entscheiden. Ich glaube aber, daß derartige Untersuchungen von der größten Bedeutung sein würden und uns für die Phylogenie der Proboszidier, für die Herkunft der. Elephanten, worüber wir so gut wie nichts wissen, einen bestimmten Weg weisen könnten. Dieser Weg würde wahrscheinlich unter Umgehung aller bekannten Stegodonten, die nur Seitenzweige darstellen, eine Brïcke zu gewissen Mastodonten direkt schlagen (siehe die Bemerkung am Schluß). Doch das nur nebenbei.

Für die Schmelzfigur hat dieser Wulst, wie gesagt, große Bedeutung. Von seiner Stärke und Höhe hängt der Charakter des Mittelteils und damit derjenige der ganzen Schmelzfigur ab. Da dieser Schmelzwulst nun, wie viele in Reduktion begriffenen Merkmale, in allen Ausmaßen seiner Gestaltung sehr schwankt bei einer Art, ja an den verschiedenen Lamellen eines Zahnes, so ergibt sich schon daraus eine gewisse Variabilität der Schmelzfigur, besonders in der 2. Gruppe von Schmelzfiguren. Es kann deshalb bei Beurteilung der Schmelzfigur der Grad und die spezielle Art der Ausbauchung oder Auszackung des Mittelstückes nicht von ausschlaggebender Bedeutung sein. Das Merkmal versagt besonders dort, wo es sich darum handelt, zwei sehr nahestehende Arten, Deszendenten, voneinander zu scheiden. Denn die eine Art hat mit der anderen meist, abgesehen von der durch Mutation hervorgerufenen Veränderung, die Hauptcharaktere der Schmelzfigur gemein and in ca. $60 \%$ der Fälle sind die Schmelzfiguren beider so gleich, daß eine Scheidung nicht möglich ist. Die durch Mutation hervorgerufenen Abänderungen aber treten bei zunehmender Abkauung mehr und mehr zurück, wie wir sogleich sehen werden, und so zeigen stark abgekaute letzte Unterkiefermolaren einer Art sehr häufig in den Schmelzfiguren völlige Übereinstimmung mit den Schmelzfiguren normal angekauter letzter Unterkiefermolaren der nächst älteren Art, des direkten Vorfahren. 
Wir haben eben dem Mittelteil der Schmelzfigur besondere Aufmerksamkeit zugewendet und ihre Verschiedenheiten kurz verfolgt. Wichtiger noch sind die Abänderungen, welche die Schmelzfigur als ganzes erleidet; wir können hier primäre und sekundäre unterscheiden. Die primären, die wir zuerst besprechen wollen, siud gesetzmäßiger Natur; und solche gesetzmäßigen Abänderungen erleidet die Schmelzfigur resp. die Lamelle in ihrem Querschnitt nach zwei Richtungen hin, die beide für die Beurteilung der Schmelzfigur, ihrer Wandlungen, Variabilität usw. von größter Wichtigkeit sind.

1. Von geologisch älteren nach jüngeren Elephanten wird aus einer breiten massigen Schmelzbüchse eine dünne Platte; vgl. die Extreme, El. planifrons und El. primigenius. Diese Veränderung kommt in der Schmelzfigur in der Weise zum Ausdruck, daß die Vorderwand und Hinterwand der Schmelzfigur näher aneinanderrücken, daß die Schmelzfigur schmäler wird. Dabei werden grobe Unebenheiten des Schmelzbleches, große Auszackungen, besonders mediane Aufbauschungen, wie sie bei phylogenetisch älteren Formen auffallen, gemildert, ja können infolge des Näheraneinanderrïckens der Lamellen und der dadurch bedingten Nivellierung der einzelnen Lamellen gänzlich verschwinden. Die Schmelzfigur kann auf diesem Wege einen ganz anderen Charakter annehmen, und nur der Erfahrene kann dann das Wichtige vom Unwichtigen unterscheiden und erkennen, daß die alten Grundcharaktere der beiden Schmelzfigurentypen erhalten geblieben sind. Die rhombische Gruppe kann bei diesem zunehmenden Zusammenrücken der Lamellen beim jüngeren El. antiquus den rhombischen Charakter mehr oder weniger verlieren, da der Raum zur Entfaltung des Mittelstückes nicht mehr zur Verfügung stelt. Man erkennt aber meistens an der größeren Regelmäßigkeit der Schmelzfigur, an der ausgeprägten Fältelung des Schmelzes die echte Antiquuslamelle wieder. Wo auch diese Kennzeichen verblassen, und auch dafür gibt es Beispiele, da bleibt der Verschmelzungstyp als untrügliches Unterscheidungsmerkmal gegen die 2. Gruppe. Diese erfährt im Laufe der Stammesgeschichte die größten Umänderungen, und nur wer mit den wichtigen Merkmalen der Schmelzfigur vertraut ist, wird die Grundcharaktere der Schmelzfigur des El. planifrons und EI. meridionalis auch bei El. primigenius herauslesen. Sie bestehen in erster Linie in dem unvermittelten Absetzen des Mittelstiicks gegen die Seitenteile, in der unregelmäß̣igen Bandform der Schmelzfigur.

$\mathrm{Zu}$ den mehr oder weniger gesetzmäßigen Abänderungen der Schmelzfigur gehören ferner die Wandlungen, die sie infolge der fortschreiten- 
den Abkauung erleidet. Wir haben oben schon die Veränderungen des Mittelpfeilers im Verlaufe der Abkauung besprochen. Hier sind auszuschließen die allerdings geringfügigeren der Seitenpfeiler und nicht zum wenigsten die schon an anderer Stelle betonten Abänderungen, die der Schmelz erleidet. $O b$ er ab- oder zunimmt an Stïrke, mehr glatt oder mehr gefältelt wird, das wirkt stark auf den Gesamteindruck der' Schlimelzfigur zurück.

Am konstantesten ist auch hier wieder die Schmolzfigur der rhombischen Gruppe. Sie behält ihre charakteristische Form zumeist his zur Basis der Lamelle bei, und die vorkommenden Abänderungen besteben eigentlich nur darin, daß die randlichen Umbiegungsstellen rundlicher und breiter werden, die Schmelzfigur also aus einem Rhombus mohr in ein Rechteck übergeht.

In der 2. Gruppe von Schmelzfiguren sind starke Abänderungen im Verlanf der Abkaung nichts Absonderliches. Bei den grenlogisch älteren Elephanten dieser Gruppe entfernt sich die Schmelzfigur derartig abgekauter Lamellen allerdings nicht so stark wie bei den jüngeren Formen rom Normaltyp. Im allgemeinen äußert sich die Veränderung nur darin, daß entweder das plötzliche Absetzen des Mittelstïckes verschwindet und die Schmelzfigur eine gleichmäßige, bandförmige Gestalt annimmt, oder darin, daß bei häufig gleichzeitiger schärferer Ahsetzung des Mittelstückes eine nicht unbeträchtliche Verzerrung der ganzen Figur Platz greift. Bei den diluvialen Formen sind die Abänderungen viel beträchtlicher. So besitzt El. trogontherii bei einem gewissen Abkauungsgrad sehr häufig typisch rhombische Schmelzfiguren, deren Ähnlichkeit mit Schmelzfiguren des El. antiquus meist noch durch ein gleichzeitiges Einsetzen von Schmelzfältelungen an der ganzen Sohmelzfigur oder nur ihres mittleren Teiles gehoben wird. Diese Figuren sind meistens an die obere Hälfte des letzten Lamellendrittels gehunden und gehen weiter unten in eine breite rechteckige Form über. Bruchstücke von Molaren des El. trogontherii, die gerade ein solches Antiquusstadium in der Abkauung erreicht haben, sind nur sehr selten von echten AntiquusMolaren zu unterscheiden. An ganzen Zähnen ist natürlich eine Fehlbestimmung schon deshalb ausgeschlossen, weil nur 2 his 3 Lamellen gleichzeitig dieses Stadium zur Schau tragen können and auch sonst durchgreifende Unterschiede vorhanden sind.

Sehr häufig bringt diese Abkauung auch Charaktere der Schmelzfigur stärker zur Erscheinung, die bei geringerer Abkanung nur sehr schwach hervortraten. Da der "Schmelzwulst" nach der Lamellenbasis wächst, so wird mit zunehmender Abkaumng die Auszackung des Mittel- 
stückes meist kräftiger, das Mittelstück selbst breiter. Derartigen Veränderungen sind besonders die Lamellen letzter Molaren ausgesetzt, besonders dic der letzten Unterkiefermolaren; denn bei diesen ganz besonders werden die Lamellen von oben nach unten kräftiger und massiger, der Schmelz meist im unteren Drittel nochmals stärker. Das gilt vor allem für die Lamellen des letzten Zahndrittels. Bei fortschreitender Abkauung rïcken daher die Schmelzwände auseinander, die Lamellen werden breiter, das Mittelstück wächst, je näher die basale Schmelzbrücke kommt, der Schmelz wird dicker und schließlich hat die Schmelzfigur eine Gestalt angenommen, wie wir sie nur bei den Vorfahren der betreffenden Art als normal kennen. So wird El. planifrons in diesem Merkmal zu El. meridionalis, dieser zu El. trogontherii; für derartige Umgestaltungen gibt es unzählige Beispiele. Stark abgekaute letzte Unterkiefermolaren können also auch in diesem Merkmal, wie in sovielen anderen, den Bestimmungsversuchen Unerfahrener verhängnisvoll werden.

2. Neben dem gesehilderten kann der Charakter der Schmelzfigur durch verschiedene Momente sekundärer Natur beeinflußt werden, die individuell sehr verschieden stark wirksam sind. Da sind zuerst die Pressionseffekte zu nennen, die infolge des eigenartigen Zahnwechsels der Elephanten auf die Zähne wirken, die sich noch in einem mehr oder weniger plastischen Zustand befinden, in ihrer Bildung noch nicht abgeschlossen sind. Ich habe 1912 S. 13 darauf hingewiesen, wie stark dadurch die Schmelzfigur verändert werden kann, besonders diejenige des vorderen und hinteren Teils der zwischen M MIII und MIII liegenden Zähne; die beiden letzteren können natürlich nur an je einer Stelle Pressionserscheinungen aufweisen. Die in Mitleidenschaft gezogenen Lamellen des vorderen und mittleren Zahnteils zeigen häufig eine völlige Zerreißung, eine Trennung in 2 Teile, sehr verbreitet eine Verzerrung der ganzen Lamelle. Auf den eigentïmlichen, schiebenden Zahnersatz ist ferner zurückzuführen das häufige Vorkommen von seitlichen Einbiegungen der Schmelzfiguren nach vorn oder hinten, wobei die ganze Schmelzfigur als mehr oder weniger deutlicher Bogen über die Kaufläche hinzieht. Dahin gehören sowohl die in der Bewegungsrichtung geschleppten Schmelzfiguren als diejenigen mit nach vorn durchgedrïcktem Mittelstück. Schmelzfiguren mit nach hinten gerichteter konkaver Krümmung gehen im Prinzip auf die gleiche Ursache zurück; sie verdanken ihr Entstehen direkt der Pression auf den vorderen Zahnteil, die den vorderen Talon in der Mitte eindrückt und die vorderen La- 
mellen, damit indirekt auch weiter hinten folgende, zum Answeichen nach hinten veranlaßt. Nach der Zahnmitte zu verblassen diese Erscheinungen meist und machen einem normalen Verlauf der Schmelzfigur Platz. Solche sekundären Abänderungen sind zwar meist lokalisiert auf die vorderen und hinteren Partien der Molaren, sie können aber dort den Charakter der Schmelzfigur in hohem Grade beeinflussen und das Charakteristische verwischen. Die Druckwirkungen sind selbstverständlich am stärksten bei Arten mit relativ dünnem Schmelz; bei El. planifrons und bei El. meridionalis sind sie von untergeordneter Bedeutung.

Für die richtige Bewertung der Schmelzfigur als Bestimmungsmoment sind nach den vorhergehenden Ausführungen erforderlich eine genaue Kenntnis vom Bau der Einzellamelle und hinreichende praktische Erfahrung. Ohne diese beiden ist es unmöglich, bei Vergleichen das Wichtige vom Unwichtigen, das Primäre vom Sekundären scheiden zu können. Die hohe Abänderungsfähigkeit der Schmelzfigur läßt es notwendig erscheinen, nur Schmelzfiguren annähernd gleich weit abgekauter Lamellen von gleichen Zahnserien zu vergleichen; womöglich auch Oberund Unterkieferzähne getrennt zu halten. Besondere Vorsicht scheint geboten bei Bewertung der Schmelzfiguren stark abgekauter letzter Unterkieferzähne, weil bei diesen meist eine beträchtliche Annäherung in der Schmelzfigur an die nächstältere Art infolge Ausschaltung der durch Mutation erworbenen Fortschritte stattfindet.

Die Schmelzfiguren der österreichischen Zähne bilden für Schlesinger ein wichtiges Bestimmungsmoment. Er bemüht sich besonders den Nachweis zu führen, daß die Schmelzfiguren des El. meridionalis von denen des El. planifrons recht verschieden wären, und daß die österreichischen Zähne mit El. planifrons in diesem Merkmal besonders gut übereinstimmten. Der Versuch Schlesingers in seiner ersten Arbeit, die Zähne des El. meridionalis und die des El. planifrons als in allen wesentlichen Merkmalen sehr verschieden voneinander und in allen Fällen, sogar bei so stark abgekauten Zähnen wie dem von Dobermannsdorf, als gut unterscheidbar hinzustellen, kontrastiert auffällig mit folgenden Ausfïhrungen in der zweiten Arbeit bei Diskussion meiner intermediären, zwischen El. trogontherii und El. antiquus stehenden Molaren:

„Das Vorhandensein intermediärer Molaren ist zumindest ebenso begreiflich bei der Ahnenschaft des El. planifrons wie des El. meridionalis, zumal die Molaren beider Arten in den Merkmalen, die Soergel anführte und die zugleich die Spezialisationsmerkmale der Zähne darstellen, sehr ähnlich sind“. Diese große Ähnlichkeit in den 
W. Soergel,

Spezialisationsmerkmalen aber - damit können nur die von mir als Variationsmerkmale bezeichneten Merkmale gemeint sein — zwischen El. planifrons und El. meridionalis hätte Schlesinger mit besserem Erfolg bei der Bestimmung des Dobermannsdorfer und Laaerberger Zahnes verwenden sollen, wo zur Bestätigung des El. planifrons allerdings die gegenteilige Ansicht erforderlich war.

Noch merkwürdiger berührt in diesem Zusammenhang folgende Äußerung S. 149: „Der Gesamtcharakter der Kaufläche von M $3 / 3$ ist für beide Arten (El. planifrons und El. meridionalis, eingefügt von Soergel) nur wenig verschieden. Die Abänderungen sind durchwegs Folgen höherer Spezialisation". Nach der letzten Äußerung lag die Ähnlichkeit in den "Spezialisationsmerkmalen", hier wird die höhere Spezialisation zur Begründung vorhandener Unterschiede herangezogen. Liegt diesem Gegensatz lediglich ein Mangel an Präzisierung zugrunde, so daß Spezialisation einmal meinen Variationsmerkmalen, einmal meinen Mutationsmerkmalen entspricht, oder läßt sich Schlesinger unwillkürlich von dem wünschenswerten Resultat über ein und denselben Gegenstand einmal zu dieser, einmal zu jener Ansicht leiten?

Die Ausführungen Schlesingers über die Unterschiede der Schmelzfiguren von El. planifrons und El. meridionalis beruhen auch wieder, wie wir sogleich sehen werden, anf Irrtümern, die einer ungenügenden Beschäftigung mit fossilem Material entspringen; den wandelbaren Charakter der Schmelzfigur und die Ursachen dieser Wandelbarkeit hat er nicht erkannt. Besonders eingehend behandelt er den Dobermannsdorfer Zahn. S. 101 der 1. Arbeit nennt er unter den Abweichungen gegen El. meridionalis:

„Die zipfelförmigen Vorsprünge nach hinten, welche bei unserem Stücke, von fast denselben Fältelungen begleitet, am letzten und vorletzten Joch auftreten, fehlen allen verglichenen typischen Molaren von El. meridionalis, finden sich dagegen in ähnlicher Ausbildung an zahlreichen Zähnen von El. planifrons, besonders schön an dem Zahn von Ferladani und dem Fragment von vier Jochen im städtischen Museum in Krems a. D." In einer Anmerkung gibt Schlesinger für zwei von Weithofer abgebildete Zähne von El. meridionalis zu, daß sie "sich in den Usurfiguren eng an El. planifrons" anschließen. Diese nicht genehme Übereinstimmung, die den Wert der Schmelzfigur natürlich in diesem Falle sofort auf Null herabdrücken würde, glaubt Schlesinger durch die Annahme paralysieren zu können „daß wir es in den beiden Typen mit Übergangsformen von El. planifrons, wenn nicht mit dieser Art selbst zu tun haben". Dieser Ausweg, der zwar an Ein- 
fachheit nichts zu wünschen übrig ließe, kann vom wissenschaftlichen Standpunkt aus kaum als befriedigende Lösung betrachtet werden, zumal Schlesinger einen Beweis für seine Behauptung gar nicht antritt. Vielmehr überzengt uns ein eingehendes Studium der Zühne von El. meridionalis, daß Zähne mit derartigen, nach Schlesinger an El. planifrons gemahnenden Schmelzfiguren gar nicht selten sind, daß besonders häufig dem Dobermannsdorfer in der Abkauung entsprechende Zähne derartige Schmelzfiguren aufweisen; in der Literatur sind solche abgekauten Zähne von El. meridionalis allerdings nur sehr selten abgebildet. Ich werde in meiner "Anleitung" an einem größeren Anschauungsmaterial aufzeigen, daß El. planifrons und El. meridionalis gerade in der Schmelzfigur sehr ähnlich sind, in vielen Fällen sogar, sobald nan nur entsprechend abgekaute Lamellen der gleichen Zahnserie vergleicht, völlig übereinstimmen bis auf wenige primitivere Charaktere der PlanifronsSchmelzfigur. Es ist recht bemerkenswert, daß zu dieser Auffassung der Sachlage alle die Autoren gelangt sind, die ihre Studien an reichem Originalmaterial vornahmen und über eine gewisse praktische Erfahrung verfügten. Von diesen Autoren nennt Schlesinger selbst Falconer, Adams, Pohlig, Weithofer.

Nach Weithofer hebt Schlesinger für die Schmelzfiguren des El. meridionalis gegenüber denen des El. planifrons besonders hervor eine nach hinten konvexe bogige Krümmung der Disken. Nun sind solche bogige Disken resp. Schmelzfiguren, die häufig auf Pressionserscheinungen zurückgehen, durchaus kein alleiniges oder gar besonderes Charakteristikum des El. meridionalis. Ferner finden wir Entsprechendes auch bei El. planifrons und zwar ganz deutlich an den ersten Lamellen des rechten im Ramus sitzenden M III mand., den Schlesinger aus der Fauna antiqua Sivalensis S. 734 seiner 2. Arbeit abbildet. Die bogige, nach hinten konvexe Krümmung der Lamellen ist sogar noch an den hinteren Lamellen sichtbar. Bei objektiver Beurteilung des zugänglichen Vergleichsmaterials erweist sich auch dieses Merkmal nicht als stichhaltig.

Für den Zahn von Dobermannsdorf ergibt sich also, daß die Schmelzfigur zur Entscheidung der Frage ob El. planifrons oder El. meridionalis vorliegt, nicht herangezogen werden kann. Im äbrigen ist die Schmelzfigur dieses Zahues so indifferent, daß sie außer für die beiden genannten Arten auch für El. trogontherii sprechen könnte, der derartige Schmelzfiguren, besonders im entsprechenden Abkauungsstadium, sehr häufig besitzt. 
Die Schmelzfigur des Laaerberger Zahnes, siehe Figur 6 auf S. 35, ist charakterisiert durch die in der Mediane aus der Hinterwand der Schmelzfigur herausspringenden groben Zacken, durch eime rundliche Expansion des Nittelteils der Vorderwand. Es ist im ganzen eine Schmelzfigur, wic sie ebenso häufig bei El. meridionalis wie bei El. planifrons vorkommt. Gerade in Auftreten dieser Expansionen zeigen die Schmelzfiguren beider Elephanten ähnliche Schwankungen, sowohl in der Stärke, als in der speziellen Art der Zackung oder Auswulstung, in dem Vorhandensein derselben auf einer oder auf beiden Seiten der Schmelzfigur. In seiner 1. Arbeit S. 106 hat Schlesinger die Art der Ausbildung dieses Merkmals bei El. planifrons in einer Tabelle zusammengefaßt, der ich folgende Resultate entnehme. Unter 11 Zähnen zeigen

5 zipfelförmige mediane Expansionen nach vorn und hinten,

2 nur nach hinten,

4 keine Zipfelbildung.

Aus diesen Zahlen kann natürlich bei dem sehr geringen Materiäl kein Schluß gezogen werden, man kann nur behaupten, daß El. planifrons in diesem Merkmal sehr schwankt, und daß, da El. meridionalis gerade in der Gestaltung der Schmelzfigur mit El. planifrons sehr gut übereinstinmt, aus der Schmelzfigur, speziell aus der graduellen Ausbildung der zipfelförmigen Medianexpansion, kein Beweis für die Zugehörigkeit eines Zahnes zu El. planifrons oder El. meridionalis ohne weiteres gezogen werden darf.

Wir kommen bezüglich des Laaerberger Zahnes zu dem Resultat, daß die Form der Schmelzfigur sowohl für El. planifrons als El. meridionalis sprechen könnte, bei einer notwendigen Entscheidung für eine der beiden Arten daher ohne Bedeutung ist.

Im Anschluß an die Besprechung der Schmelzfigur und nochmals in der 2. Arbeit bei Besprechung des Verschmelzungstyps von El. planifrons, betont Schlesinger die besondere Variabilität des El. planifrons und fährt dann fort: "Demgegenüber erscheint El. meridionalis in jeder Hinsicht als der fester geprägte Typus. Nur die ursprünglichen Stücke variieren in Merkmalen, die durchaus als Reminiszenzen an den Ahnenzustand erklärbar sind.

Die angebliche Variationsfähigkeit des späteren El. meridionalis scheint lediglich einer Mißdeutung der Tatsachen durch W. Soergel entsprungen zu sein." 
Ich muß diese Behauptungen satzweise diskutieren. Die Behauptung Schlesingers, El. planifrons sei variabler als El. meridionalis, ist leicht zu verstehen, wenn man die Arbeitsmethode Schlesingers und das publizierte Material in Betracht zieht. Auf das letztere kommt es bei Literaturarbeiten ja lediglich an. Von El. planifrons ist nur wenig Material rorhanden, so gut wie alles aber abgebildet, sowohl ganze Zähne als Fragmente in allen Abkanungsstadien. Von El. meridionalis ist ein sehr reiches fossiles Material vorhanden, die Publikationen geben in ihren Abbildungen nur das Beste, nur gute Stücke, kaum einmal Fragmente oder stark abgekaute Zähne. Derjenige, der nicht vertraut ist mit den Abänderungen, die die Schmelzfigur sowohl als auch der ganze Zahn mit der Abkauung erleiden, dem muß das unsortierte kleine Material von El. planifrons mannigfaltiger, die Art variabler erscheinen. Wer aber von El. meridionalis ein größeres Material gesehen hat, kann der Auffassung Schlesingers nicht beistimmen, ganz abgesehen rou den an anderer Stelle zu besprechenden antiquusartigen Zähnen des El. meridionalis aus dem Oberpliozän.

Der 2. Satz in Schlesingers zitierter Darlegung ist mir nicht ganz verständlich; er scheint auf einer Kombination mehrerer irrtümlicher Voraussetzungen zu beruhen, darunter wohl auch der, daß der Verschmelzungstyp bei El. planifrons intermediär sei zwischen lat. an. med. lam. und lat. lam. med. an.

Der 3. Satz enthält eine Behauptung, die Schlesinger weiterhin zu stützen versucht durch eine „kritische“ Betrachtung meiner „antiquusartigen Varietät" des El. meridionalis. Er möchte diese Form als eine Art für sich und nicht als Varietät des El. meridionalis aufgefaßt wissen, und weist auf die Ähnlichkeit der Schmelzfigur dieser Form mit El. planifrons hin, worauf ich an anderer Stelle ausführlicher eingehen werde. Die Frage, ob hier Varietät oder Art vorliegt, soll in einer anderen Arbeit, die sich mit der Stammesgeschichte der Elephanten im ganzen befaßt, ausführlich erörtert werden. Hier sei nur gesagt, daß nicht etwa nur zwei stets getrennte Typen von Molaren vorliegen, sondern daß alle möglichen Übergänge vorhanden sind in den Variationsmerkmalen. Das ist zum mindesten kein Beweis für eine artliche Trennung beider Formen auf Grund der Molaren, vielmehr werden solche Tatsachen überall gerade im gegenteiligen Sinn ausgewertet. Daß auch ein Vergleich in anderen Skelettresten uns keinen Grund geben kann, beide Formen als Arten aufzufassen, soll an anderer Stelle besprochen werden. Zwischen den Molaren ist jedenfalls eine Grenze nicht zu ziehen. 
Die von Schlesinger auf Grund seiner Literaturstudien behauptete besondere Variabilität des El. planifrous gegenüber einem den feststehenderen Typus repräsentierenden El. meridionalis beruht also a f einer Kombination von Mißdeutungen und entspringt letzten Endes, wie leider so viele Mängel der fleißigen Arbeit, aus der geringen Materialkenntnis und den unzureichenden praktischen Erfahrungen des Autors.

9. Der Winkel zwischen Kaufläche und Kronenbasis

Mit diesem Wert versucht Schlesinger ein neues Bestimmungsmoment einzuführen, das ,vor allem für die Trennung primitiver und spezialisierter Typen Bedeutung hat", oder richtiger gesagt, haben soll. "Allerdings ist es nur in jenen Fällen anwendbar, wo das hinterste Joch eben angekaut ist". Ausschlaggebend für die GröBe des Winkels hält Schlesinger die Krümmung des Kreisbogens, auf dem die Zähne bei den jüngeren Proboszidiern von ihrem Bildungsherd an die Stelle ihrer Funktion herausrücken. Dieser Kreisbogen ist natürlich parallel demjenigen, der die Zahnkrone des M III unten begrenzt, und unbestreitbar hat Schlesinger recht, wenn er ausführt, daß der Krümmungsgrad dieses Bogens von älteren nach jüngeren Proboszidiern infolge der eigenartigen Wandlung im Kicfer und Zahnbau zugenommen hat, daß er von Mastodon über Stegodon zu Elephas anwächst. Zur Unterscheidung dieser $3 \mathrm{Po-}$ sitionen in der Proboszidierentwicklung wird der Wert auch verwendbar sein; es dürfte anch ohne dieses Merkmal allerdings selten ein Zweifel darüber aufkommen, welcher von diesen Staffeln ein Zahn zugehört. Bezüglich der Unterscheidung dieser 3 Hauptformengruppen, ja vielleicht auch zur Unterscheidung der beiden Extreme innerhalb jeder dieser Gruppen mag Schlesingers Behauptung: „Diese“ (die Krïmmung des Kreisbogens) "hinwieder ist dem Spezialisationsgrad der Art proportional; der Unterschied läßt sich nun durch einen Winkel ausdrücken, dessen Schenkel von der Kaufläche und der Kronenbasis gebildet werden", Gültigkeit haben, kaum aber bei Artvergleichen innerhalb der Elephasgruppe. Hier läßt sich gegen die Argumentation Schlesingers verschiedenes einwenden.

Erstens ist der Unterschied in der Krümmung dieses Kreisbogens zwischen El. planifrons und allen seinen Deszendenten sehr minimal und könnte höchstens zwischen El. planifrons selbst und El. primigenius nennenswerte und durch Messungen einigermaßen exakt nachweisbare Unterschiede in der Größe dieses Winkels ergeben. Die 
Schwankungsbreite dieses Wertes und die Unsicherheit einer guten Messung sind hier viel zu groß, als daß sich für Bestimmungen ausschlaggebende Zahlen gewinnen lassen könnten. Zudem schwankt die Krümmung dieses Kreisbogens bei ein und derselben Art nicht unerheblich, wie sich jeder an einer größeren Anzahl intakter M III mand. überzeugen kann. Vor allen Dingen aber fragt es sich, hängt denn die Größe dieses Winkels wirklich allein, oder doch so überragend von dem Krämmungsgrad dieses Kreisbogens ab, oder sind da noch andere Momente in Rücksicht zu ziehen? Solche Momente gibt es nun eine ganze Auzahl.

1. Der Winkel wird seknndär beeinflußt dureh den Winkel, in dem die Kauflïche die Lamellen schneidet. Tieser Winkcl beträgt meistens einen Rechten oder etwas weniger. Beträgt er viel weniger, und das kommt gerade an letzten Unterkiefermolaren sehr häufig vor, die das von Schlesinger zur Messung des Winkels (Kaufläche-Kronenbasis) nötige Abkaunngsstadium erreicht haben, dann mu die Kaufläche kürzer ausfallen, als sie bei normalem Kanflächen-Lamellen-WVinkel wäre, und der Winkel Kaufläche-Kronenbasis wird größer, als er sein sollte.

2. Der Winkel wird sekundär beeinflußt durch den Grad der radialen Divergenz der letzten Lamellen. Je nachdem diese stärker oder schwächer ist, ändert sich der Winkel, den die Lamellen mit der Zahnkronenbasis bilden, und damit der Winkel zwischen der Zahnkronenbasis und einer zu den Lamellen senkrechten Fläche, eben der normalen Kaufläche. Liegen die letzten Lamellen sehr flach, also in einem dem Rechten sehr genäherten Winkel zu den Lamellen des zweiten Zahndrittels, was nicht selten vorkommt, so wird die letzte Lamelle früher die einzige unangekaute als sonst, damit in dem von Schlesinger verlangten Abkauungsstadium die Kaufläche sehr groß, damit der Winkel Kaufläche-Kronenbasis anormal klein.

3. Der Winkel Kaufläche-Kronenbasis wird beeinflußt von del absolnten Höhe des unangekauten letzten Jochos. Wie umstehende Skizze Fig. 12 zeigt, wächst dieser Winkel nit dem Höhenwert des letzten Joches. Einer Höhe der letzten Lamelle vou $55 \mathrm{~cm}$ entspricht an unserem, dem El. trogontherii von süßenborn entlehnten Beispiel ein Winkel von $35^{\circ}$, einer Höhe von 65 ein Winkel von $37^{1} / 2^{0}$, von 75 ein solcher von $51^{\circ}$, von 93 schließlich ein solcher von $60^{\circ}$. Die Höhe des letzten Joches ist bei allen Arten aber erheblichen Schwankungen unterworfen, wie wir früher gesehen haben. Diese Schwankungen erreichen bei El. trogontherii ein Ausmaß von $36 \mathrm{~cm}$. In unserem Beispiel würde einer Höhenschwankung von nur $20 \mathrm{~cm}$ aber schon eine Winkelschwankung 
von $17^{1 / 2}-20^{\circ}$ entsprechen. Wäre also bei jeder Art, wie Schlesinger irrtümlicher Weise annimmt, die Kreisbogenkrümmung konstant, so würde allein schon durch die Höhenschwankungen der letzten Lamelle das "Merkmal“ eine solche Schwankungsbreite erhalten, daß es für feinere Unterscheidungen, wie Trennung nahverwandter Arten oder direkter Deszendenten, unbrauchbar wäre. Sind die beiden vorher besprochenen Einwände ausgeschaltet, so würde der Winkel zunehmen mit wachsender Höhe der letzten Lamelle. Diese wächst aber von primitiven nach fortgeschrittenen Formen entsprechend der Höhenzunahme der ganzen Zahnkrone, allerdings mit Schwankungen. Das Wachsen des Winkels Kaufläche-Kronenbasis von älteren nach jüngeren Formen, wie es Schlesinger angibt, ist also vorwiegend eine

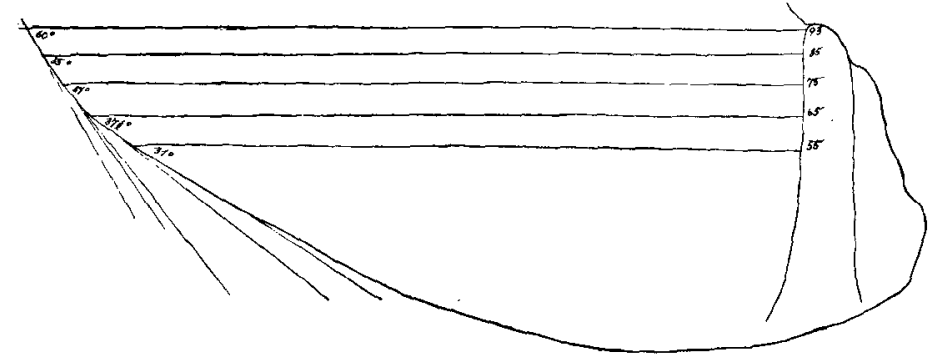

Fig. 12. Kurve der hinteren Zahnkronenbasis eines M III mand. von El. trogontherii von SüBenborn mit letzter Lamelle.

Das Schema veranschaulicht das Wachsen des Winkels Kaufläche-Kronenbasis mit dem Wachsen der Lamellenhöhe bei letzten Unterkiefermolaren mit eben angekauter letzter Lamelle.

Funktion des Höhenwachstums der Zähne. Dieser Winkel würde in rechnerischer Verkleidung - und erheblich unsicherer - also weiter nichts aussagen als das, was sich aus einem Vergleich der Kronenhöhen der einzelnen Arten ohne weiteres ergibt, daß nämlich im Laufe der Entwicklung die Zahnkrone höher wird. Durch das Eintreten der zwei anderen Momente und das graduelle Schwanken der Kreisbogenkrümmung ist aber auch hier die gesetzmäßige Verknüpfung eine sehr lose, so daß auch Zähne mit verschieden hohen letzten Lamellen gleiche Winkel, oder mit gleich hohen letzten Lamellen verschiedene Winkel bilden können. Es kommt jedesmal darauf an, welches der verschiedenen Elemente, die den Winkel beeinflussen, im gegebenen Falle dominiert.

Die Unbrauchbarkeit dieses Merkmals zur Unterscheidung primitiver und fortgeschrittener Elephanten beruht weiterhin auf der großen 
Unsicherheit der MeBmethode. Schlesinger nahm an dem Laaerberger Zahn einen Maximalwert von $15^{\circ}$, einen Minimalwert von $10^{\circ}$. Dieser Unterschied zwischen beiden möglichen Werten erscheint, besonders im Hinblick auf die im folgenden gegebenen Werte, sehr beträchtlich. An zwei gerade "richtig“ abgekauten Zähnen von El. trogontherii maß ich $25^{\circ}$ und $20^{\circ}$. Zwischen El. planifrons und El. trogontherii muß sich nun El. meridionalis einschieben, der doch sicher Winkel zwischen $15^{\circ}$ und $20^{\circ}$ aufweisen müßte, wahrscheinlich aber eine größere Schwankungsbreite zeigt. Nun besitzen zwei Zähne des El. planifrons aus dem Sewaliks nach Schlesinger $12^{\circ}$ and $16^{\circ}$, es ragt also ein Teil der Werte in die Schwankungsbreite hinein, die wir für El. meridionalis ansetzen müssen.

Wir kommen bezüglich der Verwertbarkeit dieses von Schlesinger angegebenen Merkmals zu folgendem Schluß:

Der Winkel zwischen Kaufläche und Kronenbasis hängt nicht nur von der individuell schwankenden Krümmung des Kreisbogens ab, auf dem die Zähne herausrücken. Er wird stark beeinflußt:

1. von dem Winkel zwischen Kaufläche und Lamellen,

2. von dem Grad der radialen Divergenz der letzten Lamellen,

3. besonders von der Höhe der letzten Lamelle.

Diese drei Momente bedingen neben der Unsicherheit der Messung die vollständige Wertlosigkeit des Merkmals als Bestimmungsmoment innerhalb der Elephanten. Die Möglichkeit, daß mit Hilfe dieses Merkmals El. planifrons und El. primigenius, in vielen Fällen mit einiger Sicherheit, unterschieden werden können, will ich dabei nicht in Abrede stellen. Handelt es sich um Unterscheidung sich zeitlich und phyletisch näher stehender Arten wie El. planifrons und El. meridionalis, so muß dieses Merkmal, das so stark von Besonderheiten individueller Art beeinflußt wird, völlig versagen. Die Eigenschaft des Merkmals als vorwiegende Funktion der Kronenhöhe bedingtes, daß die bei den einzelnen Arten stark abweichende Kronenhöhe auch auf dem Umwege über den Winkel KauflächeKronenbasis in vielen Fällen zum Ausdruck kommt.

Die Einführung dieses Merkmals durch Schlesinger in die Bestimmungsmethode von Elephantenzähnen beruht auf einer Verkennung der Momente, die den entscheidenden Einfluß haben auf die Größe 
dieses Winkels, und auf der falschen Voraussetzung, daß der Krümmungsgrad des Kreisbogens für die einzelnen Elephantenarten durchaus konstant, zwischen den einzelnen Arten aber merklich verschieden wäre.

\section{Zusammenfassung}

Die Behandlung der für die Bestimmung von Elephantenmolaren wesentlichen Merkmale in den Abschnitten 1 bis 8 hat für die Bewertung der Zahnfragmente von Krems, Dobermannsdorf und Laaerberg folgendes Resultat ergeben:

Es sprechen für eine Bestimmung der Zähne als El. meridionalis und gegen eine Bestimmung als El. planifrons folgende Merkmale:

1. Die Zahnhöhe.

2. Die Lamellenzahl (soweit man jhr in diesem Falle überhaupt Beweiskraft zuerkennen kann).

Für beide Arten in gleichem Maße beweisend, bei einer notwendigen Entscheidung für eine der beiden Arten daher ohne Bedeutung, sind in diesem besonderen Falle folgende Merkmale:

1. Form der Kaufläche,

2. Form der Schmelzfigur,

3. Der Verschmelzungstypus, beim Laaerberger Zahn allerdings viel mehr für El. meridionalis sprechend,

4. Der Längenlamellenquotient,

5. Die Verhältnisse des Zahnschmelzes.

Die Gestaltung der Wurzelpartie bietet in unserem Falle keinen Anhaltspunkt für Speziesbestimmungen.

Für eine Bestimmung der Zälnne als El. planifrons und gegen eine Bestimmung als El. meridionalis spricht kein Merkmal. Danach kann an der Zugehörigkeit der Zähne von Krems, Dobermannsdorf und Laaerberg zu El. meridionalis kein $\mathrm{Z}$ weifel bestehen. Bezüglich des Dobermannsdorfer und Kremser Zahnes könnte man allerdings mit dem gleichen Recht an El. trogontherii meridionalis denken.

Dieses Resultat rein palaeontologischer Erörterungen stimmt mit den geologischen Verhältnissen der Fundorte insofern überein, als für keinen von ihnen ein höheres Alter als Oberpliozän wahrscheinlich gemacht oder gar bewiesen werden konnte. Die Bestimmung dieser Zähne als El. planifrons durch G. Schlesinger beruht, wie ich leider wieder- 
holt nachweisen mußte, auf unzureichenden Kenntnissen vom Bau des Elephantenzahnes, auf mangelnden praktischen Erfahrungen in der Wertung der einzelnen Bestimmungsmomente. Hätte Schlesinger die in Aussicht gestellte Durcharbeitung des reichen im Wiener Hofmuseum aufbewahrten Elephantenmaterials vorgenommen, ehe er sich an die Bestimmung einiger für den Anfänger immerhin nicht leicht zu deutender Zähne heranwagte, so wäre El. planifrons wohl kaum zu diesem Ausflug nach Niederösterreich genötigt gewesen. Ich hoffe aber, daß ein Studium reicheren Zahnmaterials an der Hand meiner vorhergehenden Ausführungen Herrn Schlesinger bestimmen wird, der Rückkehr des El. planifrons in seine östlichen Heimatsgefilde keine Schwierigkeiten mehr in den Weg zu legen.

El. planifrons kommt also in Europa nicht vor, er ist überhaupt außerhalb Indiens bisher nicht nachgewiesen. Der von Pavlow von Ferladani als El. aff. planifrons beschriebene Zahn gehört mit den Zähnen von Stauropol und Kouialnik zu El. meridionalis, von dem sich auch im sichergestellten Oberpliozän Italiens vereinzelt derartige Zähne finden. Die Stammesgeschichte der Elephanten und die von Schlesinger auf diesem Gebiet gegen meine Auffassung erhobenen Einwendungen wird eine andere Arbeit behandeln.

Weimar, im Juni 1914.

Zu Seite 51, Zeile 17 sei noch folgendes bemerkt:

Für El. africanus hält es W. 0. Dietrich nicht für unwahrscheinlich, dab er „auf noch unbekannte jungtertiäre afrikanische Mastodonten zurückgeht". Vergl. W. O. Dietrich, Zur Stammesgeschichte der afrikanischen Elephanten, Zeitsehr. f. ind. A bstammungsl. 1913. 